IZA DP No. 7233

Unemployment Compensation and the Allocation of Labor in Developing Countries

Olivier Charlot

Franck Malherbet

Mustafa Ulus

February 2013 


\title{
Unemployment Compensation and the Allocation of Labor in Developing Countries
}

\author{
Olivier Charlot \\ THEMA, University of Cergy-Pontoise \\ Franck Malherbet \\ CREST, Ecole Polytechnique, \\ $I Z A$ and $f R D B$ \\ Mustafa Ulus \\ Galatasaray University
}

Discussion Paper No. 7233

February 2013

\author{
IZA \\ P.O. Box 7240 \\ 53072 Bonn \\ Germany \\ Phone: +49-228-3894-0 \\ Fax: +49-228-3894-180 \\ E-mail: iza@iza.org
}

\begin{abstract}
Any opinions expressed here are those of the author(s) and not those of IZA. Research published in this series may include views on policy, but the institute itself takes no institutional policy positions. The IZA research network is committed to the IZA Guiding Principles of Research Integrity.

The Institute for the Study of Labor (IZA) in Bonn is a local and virtual international research center and a place of communication between science, politics and business. IZA is an independent nonprofit organization supported by Deutsche Post Foundation. The center is associated with the University of Bonn and offers a stimulating research environment through its international network, workshops and conferences, data service, project support, research visits and doctoral program. IZA engages in (i) original and internationally competitive research in all fields of labor economics, (ii) development of policy concepts, and (iii) dissemination of research results and concepts to the interested public.
\end{abstract}

IZA Discussion Papers often represent preliminary work and are circulated to encourage discussion. Citation of such a paper should account for its provisional character. A revised version may be available directly from the author. 


\section{ABSTRACT \\ Unemployment Compensation and the Allocation of Labor in Developing Countries*}

This paper studies the effects of the introduction of unemployment compensation (UC) in countries characterized by pervasive informality. We provide a simple framework to analyze the impact of UC on the allocation of workers between formal and informal activities, as well as the allocation of workers between sectors featuring different incentives to go informal. We show that a reasonable amount of UC may reduce informality, while larger amounts of UC induce large disincentives to go formal because of the level of taxation involved. We also argue that the financing of UC should be part and parcel of a well- conceived UC system. We show that UC finance based on payroll taxes is likely to entail an excess level of informality resulting from cross-subsidies between heterogenous sectors. The introduction of a simple layoff tax meant to finance the UC system is then shown to reduce informality, hence highlighting how a well-designed financing scheme may be used as a supplementary instrument to curb informality.

JEL Classification: E24, E26, J60, L16, O1

Keywords: informality, labor market imperfections, unemployment compensation

Corresponding author:

Franck Malherbet

CREST

Macroeconomic laboratory

15, boulevard Gabriel Péri

92245 Malakoff cedex

France

E-mail: franck.malherbet@ensae.fr

\footnotetext{
* We are grateful to John Bennett, Fabian Gouret, Andrey Launov and to seminar participants at THEMA-University of Cergy-Pontoise, joint Vienna Macroeconomics Seminar, Galatasaray University and the Rouen Search and Matching Workshop for helpful comments and suggestions. The usual disclaimer applies.
} 


\section{Introduction}

Pervasiveness of informal economic activities is a prominent feature of developing countries. As emphasized by e.g. Schneider, Buehn and Montenegro (2010), informality represents on average between 30 to $40 \%$ of total employment in developing economies, much more than in high income countries. ${ }^{1}$ Broadly speaking, informal sector is beyond the reach of any kind of regulations including labor market regulations, and at the same time informal workers are excluded from the coverage of benefits associated with formal work. Nevertheless, labor market policies have direct or indirect implications on the size and composition of informal employment. In this article, we focus on the allocation of labor between formal and informal activities induced by unemployment compensation (hereafter, UC).

The incidence of UC is strongly positively related to economic development (Vodopivec, 2004, 2009). Few developing countries have UC systems, and some of them are contemplating introducing unemployment insurance. Given the significant level of informality in these nations, alongside the standard implications of $\mathrm{UC}$ on the protection provided to workers as well as on the duration and the level of unemployment, its impact on informality has to be questioned. For instance, Mexico is among the largest countries in the Americas that does not have a nationwide UC system. It is characterized by a large informal sector that accounts for about $30 \%$ of total employment. According to the OECD (2011), this reflects the limited role of income support measures for job losers, and introducing UC should be a priority for the country. The country is actually planning to introduce such a system at the nationwide level and has led experiments at a smaller scale since $2007 .{ }^{2}$

There is a large and still growing literature aimed at understanding the nature, causes and consequences of informality, especially in less advanced economies. According to the traditional dualistic approach dating back to Lewis (1954), labor markets are segmented in developing nations: the formal sector is incapable of creating enough jobs to absorb the whole active population. Hence, formal jobs are rationed. Inasmuch as it is easier to access to informal employment opportunities $^{3}$, an important portion of workers who have neither the means nor

\footnotetext{
${ }^{1}$ See also Schneider and Enste (2000) for a survey.

${ }^{2}$ An unemployment benefit scheme has been introduced in the city of Mexico. It pays unemployment benefit to persons aged 18 and older who lose their job. One of the aims of the programme is explicitly to promote the incorporation of workers into the formal economy. Over 150,000 unemployed had benefited from the scheme in 2010 .

${ }^{3}$ Informal jobs often correspond to self-employment, or can be found through social networks, friends or
} 
the time to afford waiting for a formal job accept to work in the informal sector at the expense of lower wages and absence of social protection. Consequently, informal employment can be seen as disguised unemployment. Hence, it can be argued that in the absence of state-provided UC, informal employment act as an unofficial safety net for the workers. Informality would then be much less widespread if the unemployed had access to UC. However, at the same time UC can have adverse effects on the labor demand because of the additional costs that have to be borne by the firms. If the main cause of informality is the insufficiency of labor demand in the formal sector, introducing an UC system could bring about a further increase in the size of informal sector.

There are conflicting views on the causes of informality as on the policy implications. Some recent empirical work, mostly based on evidence from Latin America, strongly challenged the traditional segmented market view and claimed that workers can voluntarily choose informal sector (see e.g. Maloney, 1999, 2004 and Pratab and Quintin, 2006). According to this desirable informal sector view, which is not new either (see e.g. Hart, 1973 and Fields, 1990), informal sector is rather a micro-entrepreneurial sector offering higher opportunities to workers with equally important mobility of workers between formal and informal jobs. ${ }^{4}$ Yet, it can be expected that introducing UC could also lead to similar opposing implications under the voluntary informal sector approach. UC will increase the payoff to searching formal jobs for the workers, while increasing the incentives for the firms to go informal in order to escape the additional burden of UC. The mechanisms proposed in this paper are compatible with both views.

The purpose of this article is to analyze the impact of UC on the allocation of workers between formal and informal activities, as well as the allocation of workers between sectors featuring different incentives to go informal. To this end, we provide a simple search and matching framework with two sectors, inspired from the Harris-Todaro model (Harris and Todaro, 1970). Consistently with the view that informality seems to be omnipresent in virtually all sectors of the economy in developing countries, we assume that within each sector, the labor market partitions itself between a formal and an informal segment: there can be both formal and informal jobs in different sectors, like, e.g. in the construction sector or in the services, while these sectors do not

\footnotetext{
relatives, so that in general, they can be found faster than formal jobs.

${ }^{4}$ In reality, the structure of the informal sector is heterogenous. For instance Fields (2005) argues that informal sector is composed of an upper tier and a lower tier. The former is in line with the voluntary informal sector view, while the latter is rather a segmented market. Accordingly, both segmented and desirable informal sector arguments partly explains the informality. A recent study by Günther and Launov (2012) shows evidence from Ivory Coast that nearly $45 \%$ of informal employment is involuntary, while $55 \%$ is voluntary.
} 
have the same proportions of formal and informal jobs. Informal jobs can be found more easily: in each sector, the formal segment is characterized by matching frictions, whereas jobs can be found instantaneously in the informal segment. Formal jobs last longer in one of the two sectors. Differences in turnover rates then induce differences in the incentives to go formal/informal. The allocation of labor within and between sectors stems from the workers' rational behavior. Formal jobs pay higher wages ex-post but they come at the expense of search costs in terms of forgone earnings in the informal sector. Workers compare expected returns from searching formal jobs with the expected returns from informal work which is decreasing in the number of informal workers. In the steady state, labor is allocated within each sector so that workers are indifferent between unemployment and informal jobs. Due to the heterogeneity in turnover rates, the risk of unemployment is more important in the high-turnover sector and implies a higher informality rate. $^{5}$ Moreover, we assume that workers are aware of their opportunities in both sectors, so search is directed. Accordingly, in equilibrium unemployed workers are equally well off in both sectors.

In this set-up, several opposite effects are at stake: UC will increase the job seekers' outside options and will make them more demanding. This will push wages up and will be detrimental to labor demand. Lower employment prospects will then lead more workers towards informality. On top of that, UC needs to be financed, and taxation will also raise the incentives to go informal. However, introducing UC also increases the returns to search for formal jobs, and could thus cause a reallocation of workers from informal towards formal work within each sector. Finally, UC may also cause a shift of the workforce between sectors where the incentives to take informal jobs differ. It is a priori ambiguous whether workers will reallocate from the sectors where the incentives to go informal are the largest to the sectors where they are the smallest following a change in UC. In any case, it is not clear which of these effects will prevail, though this may be particularly important in the context of developing countries with high unemployment and pervasive informality. Accordingly, we aim to shed light on these problems.

Our framework allows us to highlight an overall beneficial allocative effect induced by UC. We show that, at given tax rate, a rise in UC increases the returns to search for formal jobs even if job creation falls with UC. Consequently, informal activities decrease within each sector.

\footnotetext{
${ }^{5}$ Actually, any kind of heterogeneity between sectors which affects the unemployed workers expected payoffs could bring about a disparity in the sectoral informality rates. However, heterogeneity between turnover rates allows us to investigate the impact of implicit subsidies induced by UC, an issue we discuss further in the article.
} 
In addition, although each unemployed worker has a lower job finding rate, the increase in the number of job seekers could bring about a rise in aggregate formal employment. When we impose a balanced budget rule, raising UC to a reasonable amount may still reduce informality, while larger amounts of UC induce large disincentives to go formal within each sector because of the level of taxation involved. We also show that UC induces a reallocation of workers towards high-turnover sector where the informality is more widespread. Thus, the impact of UC on the inter-sectoral allocation of labor partly weakens the beneficial impact of UC on the intra-sectoral allocation of labor. Finally, UC finance creates an implicit subsidy from the low- to high-turnover sectors as the former contributes more to the financing of UC than their workers receive from the system. The subsidy causes a shift of labor force towards the high-turnover sector which in turn implies an excess level of informality. On the contrary, introducing a simple layoff tax meant to finance UC will internalize the detrimental impact of job turnover and will cause a reallocation of workers from the high- to the low-turnover sector, as well as a reduction in informality in each sector. Overall, these findings suggest that introducing UC and a well-conceived UC finance system may prove efficient in reducing informality in developing countries.

A vast literature surveyed in e.g. Mortensen (1986), Atkinson and Micklewright (1991), Holmlund (1998) or Fredriksson and Holmlund (2006) has already documented the effects of unemployment insurance (UI) on unemployment and unemployment duration, and emphasized that there is in general a positive correlation between the level and duration of UC and the length of the unemployment spell, which can lead to higher unemployment rates. Some recent work has also highlighted the potentially beneficial impact of UI on job quality (e.g. Acemoglu and Shimer, 1999, Belzil, 2001, Centeno and Novo, 2009, Tatsiramos, 2009), but those studies focus on developed rather than developing countries and do not consider informality. ${ }^{6}$ Robalino, Zylberstajn and Robalino (2011) used a search model to assess the Brazilian unemployment benefit system's effects on the transitions from unemployment to formal and informal jobs. In line with our results, their policy simulations indicate that removing UI component of the system increase the transition probabilities to informal employment both for eligible and ineligible unemployed workers. Margolis, Navarro and Robalino (2012) estimate that in the case of Malaysia, the main effect of UI would be a reallocation of labor from wage into self employment while it has only a modest negative effect on unemployment if benefits are not overly generous.

\footnotetext{
${ }^{6}$ On the contrary, van Ours and Vodopivec (2008) did not find any negative impact of reducing UI on the job quality in Slovenia.
} 
The search and matching literature has recently devoted a growing attention to the study of the labor markets of developing countries, characterized by high unemployment and high informality (e.g. Kugler, 2000, Fugazza and Jacques, 2004, Boeri and Garibaldi, 2006, Zenou, 2008, Albrecht, Navarro and Vroman, 2009, Satchi and Temple, 2009, Ulyssea, 2009, Basu, Chau, Kanbur, 2011, Charlot, Malherbet and Terra, 2011, Meghir, Narita and Robin, 2012). These studies mainly analyze the implications of labor market policies such as severance payments, payroll taxes, enforcement of regulations, subsidies and unemployment benefits on the size and composition of informal sector as well as on the whole economy in developing countries. Compared to that literature, our aim is to give a closer look at the impact of UC and UC finance on the (re)allocation of workers as well as on unemployment. In this respect, the paper closest to us is Zenou (2008). Just like we do, he proposes a Harris-Todaro type model of labor market where there are search and matching frictions in the formal market while the informal sector is perfectly competitive. Then, he investigates the impact of several labor market policies such as UI, entry costs, wage/employment subsidies and hiring subsidies on the size of informal sector and unemployment. We generalize and extend Zenou's paper in the following ways: (i) We consider not only the allocation of labor between formal and informal work within each sector, but also the allocation of labor between sectors with different incentives to go informal; (ii) We show that contrary to Zenou's claim, a rise in UC will always increase the return to search for formal jobs in each sector, in spite of the reduction in labor demand induced by UC. Therefore, UC should be increased rather than cut to reduce informality; (iii) We give a closer look at UC finance and highlight the existence of a subsidy between sectors induced by UC finance, which may cause an excess level of informality. Accordingly, we study the impact of a simple layoff tax that may reduce the subsidy.

In fact, heterogeneity in turnover rates enables us to explicitly study the impacts of UC induced subsidies and resulting allocation of labor between sectors. For the US economy, several articles (e.g. Topel and Welch, 1980, Deere, 1991, and Anderson and Meyer, 1993) have focused on the impact of UI and its finance on the cross subsidies across industries differing in the volatility of product demand they face and accordingly in their labor turnover rates. The first two have also analyzed the labor allocation effects of UI and showed that subsidized high-turnover sectors increase their labor share at the expense of less volatile sectors. For instance, both Deere (1991) and Anderson and Meyer (1993) find that construction, mining and manufacturing are 
mainly subsidized industries in most US states, whereas transportation, public utilities, finance, insurance and real estate are the losers of UI. While our focus is more on developing countries, our emphasis on differences in turnover rates between sectors is in line with their arguments, and we add to that literature a number of complementary results. In particular, we show that differences in turnover rates induce different incentives to go informal. We then study the allocative effect of UC and show that the implicit subsidy between sectors may lead to some excess level of informality which can be reduced by means of a layoff tax used in the financing of UC. Some earlier studies (e.g. Kugler, 2000 and Heckman and Pagés, 2000) showed that firing costs such as severance payments reduce turnover rates but at the same time increase informality as they reduce formal firms' labor demand. However, in our case although individual firms' firing costs increase with the layoff tax, overall fall in workers' tax contribution and in implicit inter-sectoral subsidies bring about a fall in informality.

The rest of the paper is organized as follows. Section 2 describes the model. The impact of $\mathrm{UC}$ on the divide between formal and informal activities within each sector is studied in section 3 , while section 4 studies the more general case where UC affects the allocation of labor between and within sectors. In section 5, we investigate the quantitative impact of a change in UC. Section 6 then discusses important issues related to labor turnover and UC finance. Finally, section 7 concludes. Proofs are gathered in the Appendix.

\section{The Model}

This section outlines the economic environment in which we conduct our analysis. Our model borrows from, and extends Zenou (2008), where workers trade off a risk of being unemployed when searching for a formal job, against a larger payoff when search is successful. This idea is also reminiscent of the Harris-Todaro dilemma where moving the economy from a traditional to a modern sector implies a rise in unemployment.

Time is continuous and our focus is on steady-states. The economy is composed of two sectors, denoted by $H$ and $L$. Though our model is fairly general, and can account for differences in various sectoral parameters, we will focus on differences in job destruction rates. We assume that jobs are more frequently destroyed in sector $H$ than in sector $L$, i.e. $H$ stands for highturnover sector and $L$ stands for low-turnover sector. For the sake of clarity, we start by assuming exogenous job destruction rates. Job destruction rates can easily be endogenized, as shown in 
section 6 .

Workers allocate themselves between the two sectors, while each sector partitions itself between formal/registered and informal/unregistered production activities. ${ }^{7}$ In this way, it is possible to study both the allocation of labor between sectors $H$ and $L$ (i.e. the inter-sectoral allocation of labor ), but also between formal and informal jobs (i.e. the intra-sectoral allocation of labor). As will be shown hereafter, the difference in job destruction rates implies that there are more incentives to go informal in sector $H$ than in sector $L$.

This framework allows us to generalize on Zenou (2008) by studying how changes in UC affect not only the allocation of labor between formal and informal activities within each sector, but also the inter-sectoral allocation of labor between sectors where the incentives to go formal or informal differ. Otherwise stated, our aim is to study under which condition a rise in UC may reduce informality. ${ }^{8}$

Preferences and population. The economy is populated by a continuum of workers, the size of which can be normalized to unity. Workers are assumed to be homogeneous ${ }^{9}$, infinitely lived, and risk neutral ${ }^{10}$, discounting future payoffs at rate $r>0$. Each worker supplies one unit of labor inelastically. Consumers derive utility from the consumption of an unique final good. Among sector-k's workers, $M_{k}$ and $L_{k}$ work informally and formally respectively, while there are $U_{k}$ unemployed workers searching for a (formal) job. ${ }^{11}$ The size of a sector is then defined as:

$$
N_{k}=M_{k}+L_{k}+U_{k}
$$

The size of the two sectors are related as follows from our normalization on the size of the

\footnotetext{
${ }^{7}$ There is not a unique name and definition of the informal sector phenomenon. Registration based definition is generally explained with nonconformity to fiscal and other regulations while the informal sector is associated with the activities taking place in small firms having low level of organization, with low capital intensity, and informal work relations depending on self employment and use of unpaid family workers. In this paper, informal and unregistered will mean the same thing and will be used interchangeably. For different definitions see for example Schneider and Enste (2000), Mead and Morrison (1996). It is also worth noting that Kanbur (2009) criticizes the use of generic and general definitions of the informal sector and emphasizes that the definition of the informality must be closely related to the regulation or state intervention in question.

${ }^{8}$ Of course, unemployment insurance is meant to provide insurance against unanticipated income losses to risk averse workers. Here, our objective is to analyze allocative effects of UC and not the optimal design of an unemployment insurance system. That is why we use the term unemployment compensation (UC) rather than unemployment insurance (UI).

${ }^{9}$ See Albrecht et al. (2009) or Boeri and Garibaldi (2006) for models with heterogeneous workers.

${ }^{10}$ Given our focus on the allocative role of UC rather than on its insurance role, we assume risk neutrality as a simplifying hypothesis. A similar assumption is made in e.g. Zenou (2008).

${ }^{11}$ From now on, we refer to variables related to one of the two sectors using subscript $k=\{H, L\}$.
} 
population:

$$
N_{H}=1-N_{L}
$$

The goods market. Goods are assumed to be non storable. Each sector is assumed to be specialized and produces an intermediate good which is sold on a competitive market at a price $p_{k}$. Ultimately, intermediate goods are combined to produce a final consumption good in quantity $Y$. The price of this final good is normalized to unity. The aggregate production function is CES and satisfies:

$$
Y=\left(\alpha Y_{H}^{\rho}+(1-\alpha) Y_{L}^{\rho}\right)^{\frac{1}{\rho}}
$$

where $Y_{H}$ and $Y_{L}$ denote the production of the intermediate good in the $H$ and $L$ sector respectively. As in Acemoglu (2001), $\rho<1$ and the elasticity of substitution between the two intermediate goods is $1 /(1-\rho)$, while $\alpha \in(0,1)$ is a shifter which determines the weight of the two sectors in total output.

The prices of intermediate goods, $p_{H}$ and $p_{L}$, are given by their respective marginal productivity.

$$
\begin{aligned}
& p_{H}=\alpha Y_{H}^{\rho-1} Y^{1-\rho} \\
& p_{L}=(1-\alpha) Y_{L}^{\rho-1} Y^{1-\rho}
\end{aligned}
$$

In each sector, labor is used as the sole input, and production results either from formal or informal activities. There is an endogenously sized continuum of registered firms, each endowed with a single job slot, which can be either filled and producing, or vacant and searching for a worker. Registered firms produce with a fixed coefficient technology, yielding $y$ units of output per worker. Total output realized by unregistered firms results from an aggregate production function $F\left(M_{k}\right)$ which is increasing and strictly concave in its argument. It is reasonable to assume decreasing returns for unregistered activities due to their informal nature. First of all underground activities have to take place in small markets rather than large ones. When the scope of these activities rises, they will be more visible to authorities and can be detected more easily. ${ }^{12}$ Second, the capital intensity of this sector should be low. Any worker who decides to be underground can start instantaneously to operate in this sector needless of large investments. Moreover this assumption is confirmed by some empirical works. For example, using micro data

\footnotetext{
${ }^{12}$ For instance, Fortin, Marceau and Savard (1997) analyze the impact of taxation and wage controls in a developing economy with informal sector, using a general equilibrium model. They claim that the marginal cost of labor in the informal sector is higher than the formal sector due to the higher marginal concealment costs.
} 
from a survey conducted in Quebec City, Lemieux, Fortin, and Frechette (1994) find a linear or slightly convex relation between earnings and the working hours in the regular sector, while earnings in the underground sector are a concave function of underground-sector hours.

As a result, it follows that the aggregate production of sector $k$ 's intermediate good satisfies:

$$
Y_{k}=\underbrace{y L_{k}}_{\text {formal production }}+\underbrace{F\left(M_{k}\right)}_{\text {informal production }}
$$

The Labor Market : Matching, Flow Equilibrium and Beveridge Curve. A fairly large number of empirical studies highlight that the level of unemployment is far from being negligible in developing countries and that it takes less time to find an informal than a formal job (see e.g. Meghir, Narita and Robin, 2012 for Brazil). Accordingly, we make the following assumptions on the matching processes. In formal labor markets, a Constant Returns to Scale matching function brings together in pair vacant jobs and workers, and relates the total number of contacts to the total number of firms and workers actively searching for a partner on each side of the market. Thus, the flow of hires in sector $k, \mathcal{M}_{k}$ writes:

$$
\mathcal{M}_{k} \equiv \mathcal{M}\left(\mathcal{V}_{k}, U_{k}\right)
$$

where $\mathcal{V}_{k}$ denotes the number of vacancies and $U_{k}$ the number of unemployed. The matching function $\mathcal{M}$ satisfies standard properties: it is increasing and continuously differentiable in each of its arguments, homogeneous of degree one and yields no hiring if the mass of the unemployed workers or the mass of vacant jobs is nil. Linear homogeneity of the matching function implies that it is possible to express contact rates for firms and workers as a function of a single variable, $\theta_{k} \equiv \mathcal{V}_{k} / U_{k}$, the so-called labor market tightness. On average, a vacancy meets a worker at rate $q\left(\theta_{k}\right) \equiv \mathcal{M}\left(\mathcal{V}_{k}, U_{k}\right) / \mathcal{V}_{k}=\mathcal{M}\left(1,1 / \theta_{k}\right)$, with $q^{\prime}\left(\theta_{k}\right)<0$, whereas an unemployed finds a job at rate $\mathcal{M}\left(\mathcal{V}_{k}, U_{k}\right) / U_{k}=\mathcal{M}\left(\theta_{k}, 1\right)=\theta_{k} q\left(\theta_{k}\right)$, an increasing function of $\theta_{k}$.

In informal labor markets, we assume that frictions are negligible so that workers and firms match instantaneously. This occurs when the scale parameter of the matching function tends to infinity. As a result, the informal labor market is perfectly competitive. ${ }^{13}$

The flow into unemployment results from match-specific shocks that occur at Poisson rate $s_{k}$. We assume the job separation rate to be higher in sector $H$ than in sector $L$, i.e. $s_{H}>s_{L}$.

\footnotetext{
${ }^{13}$ Several other papers also adapted the perfectly competitive informal labor market approach (e.g. Zenou, 2008, Fortin, Marceau and Savard, 1997). For a thorough discussion of modeling informal labor markets as a free-entry sector of last resort, see Fields (2005) where he states "The essence of free entry is that all who want a job can get one".
} 
The law of motion for the number of unemployed satisfies:

$$
\dot{U}_{k}=\underbrace{\left(N_{k}-M_{k}\right)\left(1-u_{k}\right) s_{k}}_{\text {number of separations }}-\underbrace{\left(N_{k}-M_{k}\right) u_{k} \theta_{k} q\left(\theta_{k}\right)}_{\text {number of hires }}
$$

where $N_{k}-M_{k}$ and $u_{k}=U_{k} /\left(N_{k}-M_{k}\right)$ indicate the size of the formal sector and the unemployment rate in sector $k$ respectively. The steady-state sectoral unemployment rate writes:

$$
u_{k}=\frac{s_{k}}{s_{k}+\theta_{k} q\left(\theta_{k}\right)}
$$

Equation (9) may be viewed as a sectoral Beveridge curve. This curve is decreasing and convex in the $\left(v_{k}, u_{k}\right)$ plane. In addition, it is straightforward to remark that $u_{k}$ is decreasing in $\theta_{k}$ and increasing in $s_{k}$.

Labor market flows and the allocation of labor within each sector (e.g. from registered to unregistered activities) or between sectors (e.g. from the high-turnover sector to the low-turnover sector) depend on firms' and workers' decisions. Such decisions are related to the asset values associated to each labor market state, which are defined in the next subsections.

\subsection{The allocation of labor and Workers' expected gains}

Let us denote by $S_{k}, W_{k}, I_{k}$ the value to the worker of being respectively unemployed and searching for a formal job, being employed on a formal job and being employed informally in sector $k$.

Intra vs inter-sectoral allocation of labor. In each sector, workers allocate themselves between formal and informal activities according to the payoffs associated with different labor market states. Ex-post value of working at formal jobs is the highest and thus formal employees do not have any incentives to take informal jobs. As for the unemployed and informal workers, they compare the payoffs from keep searching and from taking informal jobs. If the latter is higher, some unemployed workers will shift to informal activities and vice versa. However, as we assumed decreasing marginal returns from informal activities, in the steady state, workers must be indifferent between searching for a formal job and being employed by an unregistered firm. Therefore, the steady-state intra-sectoral allocation must satisfy :

$$
S_{k}=I_{k}
$$

We assume that only the unemployed can choose to reallocate themselves to a different sector, 
while on-the-job search is ruled out. ${ }^{14}$ In other words, unemployed workers are aware of their opportunities in both sectors and thus search is directed. In the steady state, the expected returns from searching in the sectors $H$ and $L$ must satisfy:

$$
S_{H}=S_{L}
$$

This relationship determines the inter-sectoral allocation of labor: workers allocate themselves between the two sectors until the expected value of searching for a job in sectors $H$ and $L$ are equalized.

Workers'expected gains. Workers' expected utility of being employed in a registered firm or unemployed and searching for a job in a registered firm can be defined as follows:

$$
\begin{aligned}
r S_{k} & =z(1-\tau)+\theta_{k} q\left(\theta_{k}\right)\left[W_{k}-S_{k}\right] \\
r W_{k} & =w_{k}(1-\tau)+s_{k}\left[\bar{S}-W_{k}\right]
\end{aligned}
$$

Job seekers in both sectors are entitled to a flat rate unemployment compensation $z$. Both income from registered employment and unemployment compensation are subject to a flat income tax $\tau$, used to finance unemployment payments. ${ }^{15}$ At rate $\theta_{k} q\left(\theta_{k}\right)$ unemployed workers will be employed leading to a capital gain of $\left(W_{k}-S_{k}\right)$. A formal worker in sector $k$ gets the net wage $w_{k}(1-\tau)$ in each period and will become unemployed at Poisson rate $s_{k}$, in which case the workers incur a capital loss given by $\left(\bar{S}-W_{k}\right)$, where $\bar{S}=\max \left(S_{H}, S_{L}\right)$, as job seekers can switch between sectors, and choose to allocate themselves to the one yielding the largest expected payoffs.

In each sector, informal labor markets are competitive, so that informal workers are paid at the value of their marginal product. Moreover, they do not contribute to the financing of the UC system. As a result, the discounted value of being informal in sector $k, I_{k}$, writes as follows:

$$
r I_{k}=w_{I_{k}}=p_{k} F^{\prime}\left(M_{k}\right)
$$

\footnotetext{
${ }^{14}$ This is a commonly shared hypothesis in numerous papers (e.g. Zenou, 2008, Fortin, Marceau and Savard, 1997). The underlying intuition can be found in Fields (1975) as he emphasizes that the informal jobs (murky sector jobs) come at the cost of reduced job search opportunities in the formal sector (modern-sector jobs). For the sake of simplicity, we adopt a stronger hypothesis and assume that informal workers have no time at all for job search.

${ }^{15} \mathrm{As}$ is the case in most OECD countries. For instance in the United States, UC are taxed on an equal basis with wages and other ordinary income since 1987.
} 


\section{$2.2 \quad$ Firms and Labor Demand}

Let us denote by $V_{k}$ and $J_{k}$, the value to the firm of holding a vacancy and a filled job respectively in sector $k=H, L$. They are defined as follows.

\section{Firms' Gains.}

$$
\begin{aligned}
& r V_{k}=-\gamma+q\left(\theta_{k}\right)\left[J_{k}-V_{k}\right] \\
& r J_{k}=p_{k} y-w_{k}+s_{k}\left[V_{k}-J_{k}\right]
\end{aligned}
$$

where $\gamma$ is the cost of holding a vacancy, assumed to be the same in both sectors. At rate $q\left(\theta_{k}\right)$, the firm meets a worker, which yields a capital gain $\left[J_{k}-V_{k}\right]$. A filled job yields instantaneous profits $p_{k} y-w_{k}$, where $w_{k}$ is the wage paid to worker. With exogenous probability $s_{k}$, the match will be destroyed and the firm incurs a capital loss $\left[V_{k}-J_{k}\right]$.

Free entry and Labor Demand. In equilibrium, free entry onto the labor market implies the expected value of a vacancy $V_{k}$ is zero. Thus using (15) and (16) one can write:

$$
\frac{\gamma}{q\left(\theta_{k}\right)}=\frac{p_{k} y-w_{k}}{r+s_{k}}
$$

Under free entry, firms enter the labor market until the expected cost of holding a vacancy $\frac{\gamma_{k}}{q\left(\theta_{k}\right)}$ equals expected profits $\frac{p_{k} y-w_{k}}{r+s_{k}}$. Equation (17) can be thought of as a labor demand function, as it implicitly defines sector-specific labor market tightness $\theta_{k}$ as an increasing function of firms expected profits, and a decreasing function of the workers' wage $w_{k}$, determined in the next subsection

\subsection{Wage Determination}

Matching Frictions in formal labor markets imply that each formal match gives rise to a surplus that has to be shared between the firm and its worker through a generalized Nash bargain, which determines wages for formal jobs according to:

$$
\max _{w_{k}}\left(W_{k}-S_{k}\right)^{\beta}\left(J_{k}-V_{k}\right)^{1-\beta}
$$

where $\beta$ and $1-\beta$ correspond respectively to the workers' and firms' bargaining strength in sector $k(0 \leq \beta \leq 1)$. The first order condition for this problem can be written as:

$$
\frac{\beta}{1-\beta}(1-\tau)\left(J_{k}-V_{k}\right)=W_{k}-S_{k}
$$


Using (12), (13), (16), and (19) with the free entry condition $V_{k}=0$, and after some simple algebra the wage equation can be written as follows:

$$
w_{k}=(1-\beta)\left[z+\frac{\beta \gamma}{1-\beta} \theta_{k}\right]+\beta p_{k} y
$$

which defines the wage as a weighted average between workers' outside options in the wage bargain $z+\frac{\beta \gamma}{1-\beta} \theta_{k}$ and the value of output $p_{k} y$. Equation (20) can be interpreted as the wage curve of the model as it defines formal wages in sector $k$ as an increasing function of labor market tightness $\theta_{k}$ : a higher labor market tightness improves workers' outside options in the wage bargain, which raises wages. In addition, it can be shown that formal jobs always pay higher wages than informal jobs, and that informal wages are higher than the net unemployment compensation (see Appendix B1 for a formal demonstration). In the (extreme) case where $\beta=0$, all workers would be paid the same wage which is equal to $z$.

\subsection{Labor market tightnesses}

Plugging the wage equation (20) in the labor demand equation (17) we can obtain the following equation for the labor market tightnesses:

$$
\frac{\gamma}{q\left(\theta_{k}\right)}=\frac{(1-\beta)\left(p_{k} y-z\right)-\beta \theta_{k} \gamma}{r+s_{k}}
$$

Equation (21) implies that for given values of the parameters of the model, there is an increasing relationship between $\theta_{k}$ and $p_{k}$ : higher prices will increase firms' expected profits, hence firms will create more vacancies.

\subsection{Arbitrage within each sector: formal vs informal jobs}

Using equations (12), (15) and (19), the return to search for a formal job in sector $k, r S_{k}$, can be rewritten as:

$$
r S_{k}=(1-\tau)\left[z+\frac{\beta \gamma}{1-\beta} \theta_{k}\right]
$$

From this expression, it turns out that the returns to search is increasing in tightness $\theta_{k}$, in UC $z$, and decreasing in the tax rate $\tau$ : a higher tightness $\theta_{k}$ implies that the unemployed will find a job more easily, which raises $r S_{k}$. More generous UC will raise the income of job seekers, which increases the value of being unemployed. Quite on the contrary, the larger the tax rate $\tau$, the lower the job seekers' net income, which reduces the return to search. Then, using the 
arbitrage condition (10) and asset equation (14), we get the steady-state number of informal workers within each sector $M_{k}$ :

$$
M_{k}=F_{k}^{\prime-1}\left(\frac{(1-\tau)\left[z+\frac{\beta \gamma}{1-\beta} \theta_{k}\right]}{p_{k}}\right) .
$$

Equation (23) implies that informal employment in sector $k, M_{k}$ is decreasing in the real returns to search in sector $\mathrm{k}, r S_{k} / p_{k}$.

\subsection{Arbitrage between sectors: high- and low-turnover sectors}

As job seekers choose to allocate themselves to the sector yielding the highest expected utility, in steady-state, we have:

$$
\theta_{H}=\theta_{L}
$$

as a result of the arbitrage condition (11) and equation (22). The inter-sectoral allocation of labor depend on tightnesses, while the intra-sectoral allocation depends on tightnesses and prices, which are taken as exogenous by workers when making their decisions. Tightnesses and prices are endogenized as shown in the next sections.

\subsection{Balanced Budget Constraint and Implicit Subsidy}

To complete the characterization of the equilibrium we need to define the government's budget constraint. The budget constraints writes:

$$
\tau\left[\sum_{k=H, L} w_{k} L_{k}+z U_{k}\right]=z \sum_{k=H, L} U_{k}
$$

In a steady state, tax revenues (the LHS of (25)) must be equal to the total unemployment benefits expenditures (the RHS of (25))for a balanced budget. It is assumed that only workers employed in formal jobs or searching for a formal job pay taxes at the same rate $\tau$ and get $z$.

Here it is in order to remark that financing of the UC system through proportional taxes paid by the workers creates an implicit subsidy between sectors. More precisely, the workers of the high-turnover sector receive an implicit subsidy from the workers of the low-turnover sector. The subsidy stems from the fact that the total tax contributions of the workers in the sector $L$ to the system is higher than the total benefits they are expected to receive when unemployed, and vice versa for the sector $H$. To illustrate our argument, let us assume first that UC is financed by a balanced budget rule within each sector, so that the contributions are equal to 
benefits in both sectors. As the job destruction rate is lower in the sector $L$ than the sector $H$, the tax rates should be also lower in the former. Then, assume that fiscal authorities switch to global financing of the system with equal taxes in both sectors. This change induces an increase of the tax rate in the sector $L$ while workers in the sector $H$ start to pay lower taxes than they should do. Accordingly, in each period the sector $H$ receives a constant subsidy from the sector $L$. The subsidy affects the allocation of workers between and within sectors, which will be considered further in the following sections. Nevertheless, we can quantify the ex-post subsidy (once the workers are allocated between and within sectors), i.e., the difference between the benefits received and the contributions to the system:

$$
T_{k}=z U_{k}-\tau\left(w_{k} L_{k}+z U_{k}\right)
$$

Note that the subsidy is negative for the sector $L$ and positive for the sector $H$.

\section{$3 \mathrm{UC}$ and the intra-sectoral allocation of labor}

In this section, we focus on the impact of UC on the intra-sectoral allocation of labor in order to show that UC will raise the incentives to search for formal jobs within each sector. This can more easily be understood by assuming that the two sectors share the same parameters, so that focusing on intersectoral movements of labor becomes irrelevant. In this case, our economy is similar to that studied in Zenou (2008). A full characterization of the more general case where a change in UC induces changes in both the intra- and inter-sectoral allocations of labor is postponed to the next section. Notice also that we proceed as in Zenou (2008) by studying the model for a given tax rate $\tau$ for analytical purposes. A balanced budget constraint is introduced in Sections 5 and 6. Endogenous taxation burdens the algebra. Therefore, we resort to numerical simulations to study the impact of a change in UC with a balanced budget constraint.

Symmetry between the two sectors implies that all endogenous variables will be equal in the two sectors. In particular, prices will be equal in the two sectors, and can be normalized to 1 . The equilibrium is then defined as follows: ${ }^{16}$

Definition 1. When sectors are fully symmetric and share the same parameters, the equilibrium is defined by a tuple $\left(u^{*}, \theta^{*}, S^{*}, M^{*}\right)$ which defines the unemployment rate, the labor

\footnotetext{
${ }^{16}$ For the sake of clarity, we drop sectoral subscripts for the moment.
} 
market tightness, the value of searching and the size of the informal sector, given by the following expressions:

$$
\begin{aligned}
u^{*} & =\frac{s}{s+\theta^{*} q\left(\theta^{*}\right)} \\
\frac{\gamma}{q\left(\theta^{*}\right)} & =\frac{(1-\beta)(y-z)-\beta \theta^{*} \gamma}{r+s} \\
r S^{*} & =(1-\tau)\left(z+\frac{\beta \theta^{*} \gamma}{1-\beta}\right) \\
M^{*} & =F^{\prime-1}\left((1-\tau)\left(z+\frac{\beta \theta^{*} \gamma}{1-\beta}\right)\right)
\end{aligned}
$$

The equilibrium can be solved recursively. Tightness, $\theta^{*}$, is the main unknown, determined by the free entry condition (28). Equation (28) defines a unique value of the labor market tightness $\theta^{*}$, as its RHS is decreasing in tightness, while its LHS is increasing. Having determined $\theta^{*}$, the values of $u^{*}, r S^{*}$, and $M^{*}$, defined respectively by (27), (29) and (30), can be directly deduced. The following proposition then summarizes the impact of a change in UC.

Proposition 1. When sectors share the same parameters, for a given tax rate $\tau$, an increase in $U C(z)$ leads to:

1. a fall in labor market tightness $\left(\theta^{*}\right)$ in the formal sector;

2. an increase in returns to search $\left(r S^{*}\right)$, and hence a fall in informal employment $\left(M^{*}\right)$;

3. a rise in unemployment $\left(u^{*}\right)$;

4. an ambiguous change in formal employment $\left(L^{*}\right)$.

Proof. see Appendix A.

The intuition of the first part of the proposition is straightforward. A rise in UC increases the workers' outside option in the wage bargain. This increases wages and reduces the expected value of a filled (formal) job, and less firms are willing to create formal jobs, so that labor market tightness $\theta^{*}$ will fall.

The impact of $\mathrm{UC}$ on informal employment $M^{*}$ depends on the impact of $\mathrm{UC}$ on the expected gain from searching for a formal job $r S^{*}$. Differentiating (29) shows that $z$ affects the returns 
to searching for a formal job via two channels:

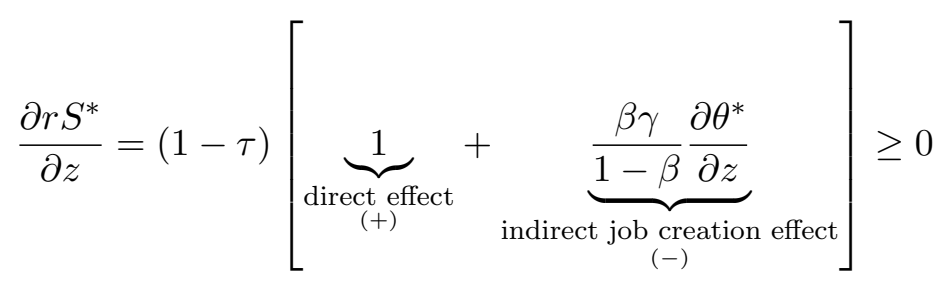

First, a direct (positive) impact, by increasing the value of remaining unemployed and second, an indirect (negative) impact, as the fall in labor market tightness reduces the job seekers' employment prospects. Differentiating (28) and reporting in (31), it turns out that the direct effect always dominates, so that the global effect is always positive, i.e. $\frac{\partial r S^{*}}{\partial z} \geq 0$.

Then, from (30), $\frac{\partial r S^{*}}{\partial z} \geq 0$ implies that informal employment $M^{*}$ will decrease when $z$ rises. ${ }^{17}$ This result contradicts that obtained in Zenou (2008), where it is argued that UC should be cut to boost labor demand and achieve a reduction in informality. We show that a rise in UC will indeed reduce labor market tightness but higher unemployment income will nonetheless attract more workers into the formal part of the economy. This reduction in informality will be achieved at the price of a higher unemployment rate, as can be inferred from (27). Notice, however, that having more unemployed workers also means having more workers participating to the formal sector. Finally, as the number of workers searching for formal jobs, $U^{*}$, increases while informality, $M^{*}$, decreases at the same time, the effect of a rise in UC on formal employment, $L^{*}$, is in general ambiguous, but could well lead to higher formal employment, $L^{*}$, provided that the impact of UC on informality is larger than its impact on unemployment. In such a case, a Todaro paradox will take place, as formal employment and unemployment will rise at the same time.

We now turn to the characterization of the model when the two sectors differ.

\section{UC and the intra- and inter-sectoral allocation of labor}

In this section, we provide a full characterization of the equilibrium when the two sectors are allowed to differ in their turnover rates, i.e. when $s_{H} \geq s_{L}$. This allows us to account for the impact of UC on the intra-sectoral allocation of labor as in the previous section, but also on the allocation of labor between sectors where the incentives to go formal differ.

\footnotetext{
${ }^{17}$ Equation (31) is similar to equation (4.2) in Zenou (2008), and our result indicates that condition (4.1) highlighted in Zenou (2008) cannot be met.
} 


\subsection{Determination of the steady-state equilibrium}

Definition 2. At given tax rate $\tau$, an equilibrium is defined by a tuple $\left(p_{k}^{*}, \theta_{k}^{*}, w_{k}^{*}, N_{k}^{*}, M_{k}^{*}, u_{k}^{*}, Y_{k}^{*}, Y^{*}\right)$ for $k=H$, L. It solves equations (3), (4), (5), (6), (20), (21), (22) and satisfies the tradeoff conditions given by (23) and (24) and the steady-state conditions on labor market flows implied by (9).

The equilibrium can be determined recursively: labor market tightnesses, $\theta_{k}^{*}$, are the two main unknown variables of the model, while all other variables are functions of tightnesses. $\theta_{k}^{*}$ can be obtained as follows. We can use equation (21) to express prices in terms of tightness as follows:

$$
p_{k}^{*} \equiv p_{k}\left(\theta_{k}^{*}\right)=\left[\frac{\gamma\left(r+s_{k}\right)}{q\left(\theta_{k}^{*}\right)(1-\beta)}+z+\frac{\beta \gamma \theta_{k}^{*}}{1-\beta}\right] \frac{1}{y}
$$

with $p_{k}^{\prime}\left(\theta_{k}^{*}\right) \geq 0$. The price $p_{k}$ is increasing in sectoral tightness $\theta_{k}^{*}$, for two reasons. First, a rise in tightness implies a rise in expected search costs for firms $\left(\frac{\gamma}{q\left(\theta_{k}^{*}\right)}\right.$ will increase $)$. Second, a rise in tightness induces a rise in labor costs, as the workers' outside options in the wage bargain, $r S_{k}^{*}$, improve with tightness. This leads to higher wages, $w_{k}^{*}$, as implied by $(20)$ which translates into a higher price, $p_{k}^{*}$.

At the same time, sectoral prices are also related by the following equation, as the price of the final good is normalized to unity:

$$
\alpha^{\frac{1}{1-\rho}} p_{H}^{*^{\frac{\rho}{\rho-1}}}+(1-\alpha)^{\frac{1}{1-\rho}} p_{L}^{*^{\frac{\rho}{\rho-1}}}=1
$$

From (33), it is straightforward to obtain that when the price of one intermediate good increases, the price of the other must fall. Accordingly, replacing equation (32) in (33) we obtain the following equation which defines a decreasing relationship between sectoral tightnesses and it will be referred to as the Pricing Curve of the model (henceforth, PC):

$$
\alpha^{\frac{1}{1-\rho}}\left[\frac{\gamma\left[r+s_{H}+\beta \theta_{H}^{*} q\left(\theta_{H}^{*}\right)\right]}{q_{H}\left(\theta_{H}^{*}\right)(1-\beta) y}+\frac{z}{y}\right]^{\frac{\rho}{\rho-1}}=1-(1-\alpha)^{\frac{1}{1-\rho}}\left[\frac{\gamma\left[r+s_{L}+\beta \theta_{L}^{*} q\left(\theta_{L}^{*}\right)\right]}{q\left(\theta_{L}^{*}\right)(1-\beta) y}+\frac{z}{y}\right]^{\frac{\rho}{\rho-1}}
$$

From this relationship, a rise in tightness in one sector implies a rise in firms' expected search costs and a rise in wages. As a result, firms will charge higher prices in that sector. In order to satisfy (33), the price must fall in the other sector, which occurs when tightness decreases in that sector, hence the negative relationship between the two tightnesses.

Tightnesses can also be positively related by the arbitrage condition between the two sectors (24) which implies that the return to search must be the same in the two sectors, yielding the 
following relationship:

$$
\theta_{H}^{*}=\theta_{L}^{*}
$$

The above equation defines an increasing (linear) relationship between the two tightnesses. It will be referred to as the Arbitrage Condition, henceforth (AC). Steady-state values of labor market tightnesses are then determined at the intersection of the PC and AC loci and can be depicted as follows in the $\left(\theta_{L}, \theta_{H}\right)$ plane:

[Figure 1 about here]

As far as effects on tightnesses are concerned, comparative statics properties of the equilibrium can be best understood from the moves of the $\mathrm{AC}$ and $\mathrm{PC}$ curves. Any increase in $s_{k}, z, \gamma, \beta$ will tend to reduce job creations and shift the PC locus downwards, while an increase in $y$ will boost job creations and shift PC upwards. On its turn, the AC locus is a $45^{\circ}$ line, implying that any change in one sector's parameters will induce a flow of labor between the two sectors until tightnesses are equalized.

A rise in job destruction in sector $k, s_{k}$, will shift the $\mathrm{PC}$ curve downward in the Figure above, leading to fall in tightness in both sectors. Namely, the increase in job destruction will reduce expected profits in sector $k$, hence the fall in $\theta_{k}^{*}$. This will also make sector $k$ less attractive, and some workers will choose to leave that sector until the arbitrage condition (AC) is satisfied, causing the fall in $\theta_{-k}^{*}$.

Similarly, an increase in $\mathrm{UC} z$, in workers' bargaining power $\beta$, or an increasing in the cost of advertising vacancies $\gamma$ will shift the PC curve downward, reducing labor market tightness in both sectors. An increase in productivity $y$ will shift PC upward, which leads to a rise in tightness in both sectors. Comparative statics properties are summarized in the following proposition:

Proposition 2. For a given tax rate $\tau$,

1. tightnesses $\theta_{k}^{*}$ and $\theta_{-k}^{*}$ decrease with unemployment compensation $z$ or sectoral turnover rates $s_{k}$ and $s_{-k}$;

2. tightnesses $\theta_{k}^{*}$ and $\theta_{-k}^{*}$ increase with productivity $y$;

3. tightnesses $\theta_{k}^{*}$ and $\theta_{-k}^{*}$ decrease with workers'bargaining power $\beta$; 
4. tightnesses $\theta_{k}^{*}$ and $\theta_{-k}^{*}$ decrease with job creation costs $\gamma$.

Proof. see Appendix B3.

An important implication of the above proposition is the more widespread informality in the sector $H$. Suppose that there is no UC and starting from a symmetric equilibrium, $s_{H}$ increases. As already explained, the fall in the $\theta_{H}$ will shift some unemployed workers to the sector $L$ until $\theta_{k}$ and $r S_{k}$ equalize between sectors once again. Consequently, the output in the sector $L$ will increase relative to the sector $H$ and $p_{L}$ will decrease while $p_{H}$ will increase. Although the value of unemployment is now equal, higher returns from informal work due to higher $p_{H}$ (see equation (23)) bring about a higher rate of informality in the sector $H$. Let us now focus on the impact of a change in $z$ on the intra- and inter-sectoral allocation of labor.

\subsection{UC and Labor Allocation Between and Within Sectors}

We now investigate the effects of UC on the allocation of labor, within and between sectors when $s_{H} \geq s_{L}$. They are summarized in the following proposition.

Proposition 3. Assume that $s_{H} \geq s_{L}$ and that the two sectors are identical in all other respects. For a given tax rate $\tau$, an increase in $z$ leads to:

1. an increase in the returns to search for formal jobs in both sectors $r S_{H}^{*}$ and $r S_{L}^{*}$;

2. an increase in the size of high-turnover sector, $N_{H}^{*}$, and a decrease in the size of the low turnover sector, $N_{L}^{*}$;

3. a fall in the price of intermediate good in the high turnover sector, $p_{H}^{*}$, and a rise in the price of intermediate good in the low-turnover sector, $p_{L}^{*}$;

4. a fall in informal employment in both sectors $M_{H}^{*}$ and $M_{L}^{*}$;

5. a rise in unemployment rates $u_{H}^{*}$ and $u_{L}^{*}$;

6. an ambiguous change in formal employment $L_{H}^{*}$ and $L_{L}^{*}$.

Proof. see Appendix B4. 
The intuition is the following. As in the previous section, a rise in $z$ impacts the return to search $r S_{k}^{*}$ via a positive direct effect, and via a negative indirect effect through tightness. The direct effect dominates so that the return to search increases with UC as claimed in (1.).

A rise in UC will reduce labor demand in both sectors, but for given prices equation (21) implies that the initial fall in the low-turnover sector will be more important as $s_{H} \geq s_{L}$. Therefore, the return to search will initially rise relatively more with $z$ in sector $H$ than in sector $L$. Put differently, workers will be reallocated from the low-turnover sector to the highturnover sector following a rise in $z$ as claimed in (2.). Accordingly, the size of the high-turnover sector, $N_{H}$, will increase until tightnesses and returns to search are equalized between the two sectors.

The rise in the returns to search, $r S_{k}^{*}$, increases the workers' outside options in the bargaining and implies higher wages $w_{k}^{*}$ but also reduces tightnesses $\theta_{k}^{*}$ in both sectors. This induces two opposite effects on prices: (i) firms tend to charge higher prices as a result of higher wages, but (ii) lower tightnesses reduce firms expected search costs $\frac{\gamma\left(r+s_{k}\right)}{q\left(\theta_{k}^{*}\right)}$, and implies lower prices. The wage effect (i) dominates in the low turnover sector, while search costs have to be paid more frequently in the high turnover sector, so that the search cost effect (ii) dominates the wage effect (i) in sector $H$. As a result, prices move in opposite directions in the two sectors, as claimed in (3.).

With heterogeneous sectors, the divide between formal and informal activities is now determined by $F^{\prime}\left(M_{k}^{*}\right)=\frac{r S_{k}^{*}}{p_{k}^{*}} \cdot{ }^{18}$ In the high-turnover sector the rise in $r S_{H}^{*}$ combined with the fall in $p_{H}^{*}$ directly imply a decrease in the number of informal workers, $M_{H}^{*}$. As for the low-turnover sector both $r S_{L}^{*}$ and $p_{L}^{*}$ increase. However, the rise in the former is more important than the increase in the latter. Consequently, the number of informal workers, $M_{L}^{*}$, also declines in that sector, as claimed in (4.). Therefore, the result of the previous section generalizes to the case of heterogenous sectors.

As for unemployment, lower tightnesses translate into lower job prospects in both sectors, which increases sectoral unemployment rates $u_{k}^{*}$, as claimed in (5.).

\footnotetext{
${ }^{18}$ In the Appendix, we show that the analogue of condition (31) now writes:

$$
\operatorname{sign}\left\{\frac{\partial\left(r S_{k}^{*} / p_{k}^{*}\right)}{\partial z}\right\}=\operatorname{sign}\left\{\epsilon_{r S_{k}^{*} / z}-\eta_{k} \epsilon_{\theta_{k}^{*} / z}\right\} \geq 0
$$

where $\eta_{k}=-\theta_{k}^{*} \frac{q^{\prime}\left(\theta_{k}^{*}\right)}{q\left(\theta_{k}^{*}\right)} \in[0,1]$ denotes the elasticity of the matching function with respect to unemployment, while $\epsilon_{r S_{k}^{*} / z}=z \frac{d r S_{k}^{*} / \partial z}{r S_{k}^{*}} \geq 0$ and $\epsilon_{\theta_{k}^{*} / z}=z \frac{\partial \theta_{k}^{*} / \partial z}{\theta_{k}^{*}} \leq 0$ denote respectively the elasticity of the return to search $r S_{k}^{*}$ with respect to $z$, and the elasticity of tightness $\theta_{k}^{*}$ with respect to $z$.
} 
The impact of UC on formal employment in each sector is ambiguous, and results from:

$$
\frac{\partial L_{H}^{*}}{\partial z}=\underbrace{-\overbrace{\partial u_{H}^{*}}^{(+)}\left(N_{H}^{*}-M_{H}^{*}\right)}_{(-)}+\underbrace{\left(1-u_{H}^{*}\right)(\frac{\overbrace{\partial N_{H}^{*}}^{(+)}}{\partial z}-\overbrace{\frac{\partial M_{H}^{*}}{\partial z}}^{(-)})}_{(+)}
$$

and

$$
\frac{\partial L_{L}^{*}}{\partial z}=\underbrace{-\overbrace{\partial u_{L}^{*}}^{(+)}\left(N_{L}^{*}-M_{L}^{*}\right)+\left(1-u_{L}^{*}\right) \frac{\overbrace{\partial N_{L}^{*}}^{(-)}}{\partial z}}_{(-)}+\underbrace{\left(1-u_{L}^{*}\right)\left(-\frac{\overbrace{\partial M_{L}^{*}}^{(-)}}{\partial z}\right)}_{(+)}
$$

In each sector, the change in formal employment is made up of three components. First, the change in unemployment due to higher $z$; second, at given unemployment rate, the change in the number of workers in each sector; finally, the change in the number of workers deciding to go informal. The unemployment effect is negative in each sector, as argued in (5.), while the participation effect is positive in sector $H$ and negative in sector $L$, as argued in (2.). Finally, the informality effect is positive in each sector, as argued in (4.). Overall, the impact of $z$ on formal employment is ambiguous, but could well be positive, leading again to a Todaro paradox, as in the previous section.

A few additional remarks on the impact of UC on the inter-sectoral reallocation of labor are in order: First, the value of unemployment will increase with UC in both sectors, but for given prices the rise in $r S_{H}$ will be more important, as already explained. Therefore, if there was no inter-sectoral allocation of workers, the fall in the informal sector would also be higher in the sector $H$ than the sector $L$ as workers having a higher risk of unemployment will value the UC more. Second, workers' shift towards high-turnover sector will reduce $\theta_{H}$ and $r S_{H}$, and increase $\theta_{L}$ and $r S_{L}$ until the arbitrage condition is satisfied. In other words, for given prices, the intersectoral move of workers partly weakens the potentially beneficial impact of UC in reducing informality in the sector $H$ while it intensifies the fall in informality in the sector $L$. Third, the prices will not stay constant in the equilibrium. The fall in $p_{H}$ raises the real returns to search $r S_{H} / p_{H}$ while the increase in $p_{L}$ makes informal jobs more valuable. Accordingly, in terms of reducing informality, the price changes caused by the movement of workers between sectors will have additional positive effects in the sector $H$, whereas negative effects will be encountered in the sector $L$. Finally, the change in the implicit subsidy between sectors following a rise in UC also has to be mentioned. Higher UC will increase the subsidy for two reasons: First, for given sizes of two sectors, higher level of benefits implies that the difference between tax contributions 
and expected benefits will increase in both sectors, but in opposite directions. Second, shift of workers towards high-turnover sector translates into a higher number of unemployed workers receiving subsidy, even for given tax rates.

We now turn to a quantitative evaluation of UC induced effects.

\section{Quantitative impact of UC on labor allocation}

In this section, we close the model by introducing a balanced budget constraint, and parameterize the model to explore its quantitative properties. The model is first parameterized to be representative of a developing economy without any UC system, characterized by a substantial degree of informality within each sector. The heterogeneity in turnover rates between sectors leads to larger incentives to take informal jobs in sector $H$ than in sector $L$. Next, we introduce UC to evaluate its impact on the allocation of workers within each sector and between sectors. We show that the introduction of a reasonably low amount of UC may lead to a rise in formal employment and a decrease in informality. However, a rise in UC will induce a rise in the tax rate: above a certain level, the rise in taxes induced by UC will counteract the beneficial impact of UC, and will deter workers from entering the formal sector. Further investigation on UC finance is therefore provided in section 6 .

\subsection{The benchmark economy without UC}

Parameters are chosen with two criteria in mind. First, they have to be realistic and coherent with the values usually used in the literature. Second, the values of the endogenous variables stemming from the simulations have to be realistic and/or comparable with the values found in previous studies. The choice of parameters does not reflect a specific economy, and corresponds broadly to the parameters of an 'average' developing economy. The time period is set to a year and the annual discount rate $r$ is set to $5 \%$. The matching technology is Cobb-Douglas and satisfies $\mathcal{M}\left(\mathcal{V}_{k}, U_{k}\right)=c_{k} \mathcal{V}_{k}^{1-\eta_{k}} U_{k}^{\eta_{k}}$ where $c_{k}$ is a mismatch parameter and $\eta_{k}$ is the elasticity of the matching function with respect to unemployment. We assume $\eta_{k}$ to be equal to $\frac{1}{2}$ which is in the range of the estimates obtained by Petrongolo and Pissarides (2001) and is a commonly accepted value in the literature. The production function in the informal sector is increasing and concave and defined as $F\left(M_{k}\right)=a_{k} M_{k}^{\mu_{k}}$ where $0<\mu_{k}<1$ is the elasticity of the production function with respect to $M_{k}$ and $a_{k}>0$ is a scalar meant to reflect productive efficiency in 
the informal sector. We proceed as in Zenou (2008), and parameterize our benchmark economy without UC to obtain an economy where roughly $50 \%$ of the workers are employed in the formal sector, $40 \%$ in the informal sector and the remaining $10 \%$ are unemployed and searching for a formal job. Baseline parameters are reported in Table 1.

Table 1: Benchmark parameters values

\begin{tabular}{|c|c|c|c|c|c|}
\hline \multirow[t]{2}{*}{ Parameter } & \multicolumn{2}{|c|}{ High turnover sector } & \multicolumn{2}{|c|}{ Low turnover sector } & \multirow[t]{2}{*}{ Description } \\
\hline & Formal & Informal & Formal & Informal & \\
\hline$y$ & 1 & - & 1 & - & Productivity \\
\hline$a$ & - & 0.6 & - & 0.6 & Productivity scalar \\
\hline$\mu$ & - & 0.6 & - & 0.6 & Labor elasticity \\
\hline$\gamma$ & 0.3 & - & 0.3 & - & Cost of a vacancy \\
\hline$s_{k}$ & 0.2 & - & 0.1 & - & Separation rate \\
\hline$c$ & 0.8 & - & 0.8 & - & Mismatch parameter \\
\hline$\beta$ & 0.5 & - & 0.5 & - & Bargaining power \\
\hline \multicolumn{6}{|c|}{ General parameters } \\
\hline$r$ & \multicolumn{4}{|c|}{$5 \%$} & Discount rate \\
\hline$\alpha$ & \multicolumn{4}{|c|}{0.5} & Weight of the high turnover sector \\
\hline$\rho$ & \multicolumn{4}{|c|}{1.5} & Elasticity of substitution \\
\hline$\eta$ & \multicolumn{4}{|c|}{0.5} & Matching elasticity \\
\hline$z$ & \multicolumn{4}{|c|}{0} & Unemployment benefits \\
\hline
\end{tabular}

The steady state equilibrium values of the benchmark economy are reported in Table 2 below. The resulting aggregate variables appears to be reasonable. They are for instance in

Table 2: Equilibrium values

\begin{tabular}{lccc}
\hline & High turnover sector & Low turnover sector & Description \\
\hline$L_{k}$ & 0.1693 & 0.3403 & Number of employees \\
$U_{k}$ & 0.0396 & 0.0398 & Number of unemployed \\
$M_{k}$ & 0.2460 & 0.1650 & Number of shadow workers \\
$u_{k}$ & $18.97 \%$ & $10.48 \%$ & Sectoral unemployment rate \\
$\frac{M_{k}}{N_{k}}$ & 0.5408 & 0.3027 & Share of the informal sector \\
\hline \multicolumn{4}{c}{ Aggregate (Both sectors) } \\
\hline$u$ & $13.49 \%$ & Unemployment rate \\
$M$ & $50.95 \%$ & Employment rate \\
$M$ & $41.10 \%$ & Informality rate \\
\hline
\end{tabular}

accordance with the estimates of Schneider, Buehn and Montenegro (2010) of the size of the informal sector in Latin America and the Caribbean. The unemployment rate is in line with the 
figures presented in Heckman and Pages (2003).

\subsection{The economy with UC}

In this subsection we give a closer look at the consequences of introducing UC under a balanced budget constraint. Under endogenous taxation, increasing UC also increases taxes. On its turn, the rise in taxes may counteract the beneficial effect of $\mathrm{UC}$ on the incentives to go formal, as the tax rate induces both a direct negative impact on the returns to search, and an indirect negative effect through labor demand. Figure 2 depicts the impact of UC on the intra and inter-sectoral allocation of labor.

\section{[Insert Figure 2 here]}

Within each sector, the introduction of a reasonably low amount of UC reduces the number of informal workers, though the fall is especially small in sector $L$. However, above a certain level of UC, the negative impact of the tax rate on the returns to search dominates the direct impact of $z$ in both sectors. UC also alters the allocation of workers between sectors. Intuition is similar to subsection 4.2. UC has a positive impact on the returns to search in both sectors, but its impact is larger in sector $H$. Accordingly, some unemployed workers in the sector $L$ prefer to switch to sector $H$. The flow of workers continues until the tightnesses and returns to search once again equalize between two sectors. The shift of labor force implies a change in the relative prices of intermediate goods: $p_{H}$ falls and $p_{L}$ rises. Lower $p_{H}$ reduces the real returns to informal activities and accordingly strengthens the incentives to leave informal jobs in sector $H$. On the contrary, increased $p_{L}$ makes informal jobs more attractive for the workers of sector $L$, which explains the limited fall in informality, even for the low amounts of $z$.

With the help of an additional numerical exercise, we can now disentangle between the 'pure' impact of UC on the inter-sectoral allocation of labor in the absence of cross-subsidies between sectors from the impact of UC induced by the implicit subsidy. Following an increase in $z$ from 0 to 0.1 , Table 3 displays the decomposition of the growth rate of real returns to search, which determines the level of variation in informal activities. The first column labeled 'UC' represents the growth (in \%) of $r S_{k} / p_{k}$ stemming solely from UC without the implicit subsidy, while the second column labeled 'Subsidy' displays its growth brought about by the implicit subsidy. 
Table 3: Decomposition of the growth rate of the real returns to search following an increase in unemployment compensation from $z=0$ to $z=0.1$. Values are expressed in percentage.

\begin{tabular}{cccc}
\hline \hline & UC (\%) & Subsidy (\%) & Total (\%) \\
\hline$\frac{r S_{H}}{p_{H}}$ & 0.73 & 1.54 & 2.27 \\
$\frac{r S_{L}}{p_{L}}$ & 1.16 & -0.91 & 0.25 \\
\hline
\end{tabular}

The logic of the decomposition can be explained as follows: in a first step, we run a counterfactual exercise and impose a balanced budget constraint within each sector, so that the cross subsidization vanishes. In this case, the tax rate will be higher in sector $H$ than in sector $L$. Following an increase in UC, the rise in $r S_{k} / p_{k}$ will hence reflects the 'pure' effect of UC. In a second step, the cross subsidization channel is reactivated, as is the case with the balanced budget rule (25). The last column from Table 3 follows. The subsidy effect therefore obtains from the difference between the last and the first column from Table 3. This brings about an additional effect on $r S_{k} / p_{k}$, as can be observed from the second column from Table $3: r S_{H} / p_{H}$ will be further increased and $r S_{L} / p_{L}$ will be lowered by the subsidy due to the change in taxation at the sectoral level. Otherwise stated, the implicit subsidy from the low- to the high-turnover sector increases the real return to search in the subsidized sector. It can be observed from Table 3 that nearly two thirds of the total change in the real return to search following a rise in UC is due to the positive subsidy in the sector $H$, while the negative subsidy substantially reduces the impact of UC on the real return to search in sector $L$.

In summary, the sector where the incentives to go informal are the smallest would be larger, with a lower informality rate in the absence of cross subsidization.

\section{[Insert Figure 3 here]}

Figure 3 displays the impact of UC on the aggregate number of informal workers as a function of the degree of heterogeneity between the two sectors, captured by the ratio $s_{H} / s_{L}$. Globally, informality always decreases for reasonably low values of $z$. However, the impact of UC on informality is stronger when there is more heterogeneity between sectors. When the degree of heterogeneity is high, inter-sectoral allocation of workers is sizeable and consequently, the price changes are also more important. In this case, the fall in the number of informal workers mainly results from the decline of informality in the sector $H$, as higher $p_{L}$ significantly reduces the incentives to search for formal jobs in sector the $L$. 
[Insert Figure 4 here]

As for unemployment, Figure 4 shows that it increases with UC because of lower labor demand within each sector. Moreover, as higher UC leads some workers towards the more volatile sector where the incidence of unemployment is higher, the overall rise in unemployment is stronger when the the two sectors are more heterogeneous in terms of job destruction rates.

\section{$6 \quad$ UC finance and informality}

It has been assumed so far that UC was exclusively financed through a proportional payroll tax. Though realistic, this assumption creates cross-subsidies at the sectoral level that are likely to entail an excess level of informality as argued in the previous section.

In this section, we aim at further investigating how UC finance affects the allocation of labor in an economy with pervasive informality. With this feature in mind, we introduce a supplementary instrument to finance UC that takes the form of a simple layoff tax. The logic behind this instrument is to some extent reminiscent of an experience-rated system as is common in the United States (US).

The impact of UC finance on the allocation of labor has already been considered in the context of more advanced economies. In the US, it has been shown that the low-turnover sectors generally subsidize the high-turnover sectors : for instance, Deere (1991) and Anderson and Meyer (1993) have shown that the construction sector in the US consistently receives subsidies from the UC system. As already explained, the subsidy originates from the fact that firms in more stable sectors pay more to the UC system than their workers are expected to receive in benefits when fired. It follows that the more volatile sectors are subsidized by the more stable ones. Feldstein (1976) argued that payroll taxes used to finance UC give rise to inefficiently high levels of layoffs, as firms do not internalize the cost of their layoff decisions for the UC system. To avoid this phenomenon, UC should be financed by a layoff tax that reduces the extent of the subsidy from low- to high-turnover sectors.

Similar arguments apply in our model: in sector $H$, taxes paid are less than the benefits received on average, so that employment in sector $H$ is subsidized by the contribution of sector $L$ to the UC system, where the benefits workers receive on average are lower than taxes paid. By reducing the subsidy, the introduction of a layoff tax could make sector $H$ less attractive and reduce informality. 


\subsection{Endogenizing job destruction rates}

In order to study the implicit subsidy between sectors implied by UC finance and the impact of the layoff tax on informality, we extend our model to account for endogenous job destruction in the spirit of Mortensen and Pissarides (1994). ${ }^{19}$

More specifically, we endogenize the sectoral job destruction rate $s_{k}$ by introducing productivity shocks in the model. Let us assume that each job is endowed with a random, job-specific productivity parameter $y$ drawn from a stationary and known-by-all distribution function $G(y)$ with support over the range $\left[y_{\min }, y_{\max }\right]$. For the sake of simplicity, it is assumed that the productivity of new matches is equal to $y_{\max }$. The stochastic process governing productivity shocks is Poisson with arrival rate $\lambda_{k}$. When a shock occurs, a new value of the productivity is drawn from the cumulative distribution $G(y)$. If the new productivity value is below an endogenous threshold denoted $R_{k}$ the job-worker match is dissolved, otherwise the match continues with its new productivity level, $y \geq R_{k}$. It follows that the job destruction rate of the previous sections is now defined as $s_{k} \equiv \lambda_{k} G\left(R_{k}\right)$. We shall assume $\lambda_{H}>\lambda_{L}$, while the two sectors are identical in all other respects, so that we still have $s_{H}>s_{L}$ as in the previous sections. With these features in mind, we now turn to the study of UC finance, while the details of the extended model are left to Appendix C.

\subsection{UC Finance and the implicit subsidy between sectors}

Budget constraint: UC is henceforth financed by two instruments. The first instrument is, as before, a proportional payroll tax, $\tau$ which is levied on all formal workers, irrespective of their status on the labor market. The second one is a sector-specific layoff tax, $\tau_{f_{k}}$, paid each time a match is severed. This modeling makes it possible to create a mix of two systems which are used to finance UC. In this setting, the balanced budget rule (25) rewrites as:

$$
\underbrace{\tau \sum_{k}\left(\omega_{k}+z U_{k}\right)}_{\text {workers' contribution }}+\underbrace{\sum_{k} L_{k} s_{k} \tau_{f_{k}}}_{\text {layoffs' contribution }}=\sum_{k} z U_{k}
$$

where $\omega_{k}$ defines the sector- $k$ wage bill. ${ }^{20}$ This constraint deserves some comments. The LHS corresponds to the resources collected by the UC system and is composed of two terms: (i) the

\footnotetext{
${ }^{19}$ Endogenous job destruction makes the introduction of the layoff tax to finance UC more relevant as sectoral job creation and job destruction will be affected by the tax.

${ }^{20}$ Note that as is conventional in the literature (see Mortensen and Pissarides, 1999, p. 2594), the layoff tax modifies the shape of wage bargaining and implies a two-tier bargaining structure. It requires to distinguish between the initial stage upon first meeting (indexed by $o$ ) and the following stages (indexed by $i$ ). Formally the
} 
workers' contribution as in the previous sections, and (ii) the layoffs' contribution. The second term indicates that part -if not all- of the UC system can be financed thanks to a layoff tax. Other things being equal, it must be noted that the layoffs' tax is increasing in the (endogenous) job destruction rate, $s_{k}$. The RHS corresponds to the total amount of UC provided to the workers. Rearranging (35) yields the tax rate $\tau$ as a decreasing function of the layoff tax $\tau_{f_{k}}$ :

$$
\tau=\frac{\sum_{k} z U_{k}-\sum_{k} L_{k} s_{k} \tau_{f_{k}}}{\sum_{k}\left(\omega_{k}+z U_{k}\right)}
$$

Otherwise stated, the layoff tax partly internalizes the fiscal burden of firms' firing decisions.

Subsidy: The sector- $k$ subsidy may be either positive (the benefits received in that sector exceed the taxes paid) or negative (the taxes paid in that sector exceed the benefits received). The subsidy, $T_{k}$, writes:

$$
T_{k}=z U_{k}(1-\tau)-\tau \omega_{k}-\tau_{f_{k}} L_{k} s_{k} \lesseqgtr 0
$$

Layoff tax: We now proceed to the determination of the layoff tax $\tau_{f_{k}}$. In the event of a separation, it is set according to a fiscal-cost criterion as follows: given that the exit rate from unemployment in sector $k$ is $\theta_{k} q\left(\theta_{k}\right)$, the expected discounted cost of an unemployed worker is $\frac{z}{r+\theta_{k} q\left(\theta_{k}\right)}$. Then, that the layoff tax may be written as:

$$
\tau_{f_{k}}=\frac{e z}{r+\theta_{k} q\left(\theta_{k}\right)}
$$

where $e \in[0 ; 1]$ is an index of the coverage of the layoff tax, i.e. the share of the expected fiscal cost that is directly borne by the firm at the time of the layoff. ${ }^{21}$ A few remarks are in order. First, it is increasing in UC, $z$, and in the coverage index, $e$. Hence, the higher these two components, the higher the expected cost of an unemployed worker to a firm at the time of the layoff. Second, it is decreasing in labor market tightness: the higher $\theta_{k}$, the lower the average unemployment spell and as a consequence the lower the cost borne by the firm. Third, the tax is sector-specific to the extent that it is indexed on the average length of unemployment spells $\frac{1}{\theta_{k} q\left(\theta_{k}\right)}$. Notice that even if the arbitrage condition (AC) implies that in equilibrium, tightnesses are equalized so that the equilibrium layoff tax will be the same in the two sectors, the layoff average wage bill in sector $k$ verifies $\omega_{k}=L_{o_{k}} w_{o_{k}}\left(y^{\max }\right)+L_{i_{k}} \int_{R_{k}}^{y^{\max }} w_{i_{k}}(\zeta) \frac{\mathrm{d} G(\zeta)}{1-G\left(R_{k}\right)}$ with $L_{k}=L_{o_{k}}+L_{i_{k}}$. See Appendix $\mathrm{C}$ for furthers details.

${ }^{21}$ More specifically, imagine that the fiscal cost of an unemployed worker to the UC system writes in its simplest form as $r C_{k}=z_{k}+\theta_{k} q\left(\theta_{k}\right)\left[0-C_{k}\right]$ and that the layoff tax borne by the firm amounts to a share of the fiscal cost so that $\tau_{f_{k}}=e C_{k}$. The layoff tax, $\tau_{f_{k}}$, then obtains from the combination of these two expressions. 
tax will still help to reduce the subsidy from sector $L$ to sector $H$. Namely, the amount of the tax paid for each job destruction will be the same in the two sectors, but jobs are more often destroyed in sector $H$, so that even in this case, firms will on average contribute more to UC finance than in the absence of such a tax.

\subsection{How does UC finance affect the allocation of labor?}

Let us now look at the consequences of introducing a layoff tax in our economy. Figure 5, 6, and 7 below depict how the allocation of labor -within and between sectors- and unemployment are altered by a rise in the coverage index.

[Figure 5 about here]

At first glance, it can be remarked that the increase in the coverage index drives down the size of the volatile sector, $N_{H}$, and foster the development of the stable sector, $N_{L}$, as expected. This is the consequence of a reduction in the implicit subsidy $T_{H}$.

In addition, within each sector, the introduction of the layoff tax is efficient in reducing the number of informal workers. The layoff tax reduces the implicit subsidy between sectors, and therefore reduces informality for two reasons: (i) The layoff tax reduces the incentives to take informal jobs within each sector due to the reduced payroll tax. (ii) The reduction in informality is further amplified by the fact that a lower subsidy from sector $L$ to sector $H$ makes the latter less attractive to workers compared to the former. The fall in the subsidy thus leads to a reallocation of workers from sector $H$ to sector $L$ while sector $L$ features less informal workers than sector $H$.

[Figure 6 about here]

It can also be remarked that the impact of the layoff tax on informality is fostered as the ratio $\lambda_{H} / \lambda_{L}$ increases, i.e., when there is more sectoral heterogeneity.

[Figure 7 about here]

Looking at Figure 7, it appears that the unemployment rate unambiguously decreases and that this decrease is again magnified by the difference in turnover rates between the sectors. The effect of the layoff tax on unemployment deserves some comments. At first sight, this tax acts exactly as firing costs and distorts the decisions of the firm to create (lower hiring) and terminate 
jobs (more labor hoarding). ${ }^{22}$ This tax has however a fiscal counterpart through the balanced budget rule (see eq. 35). As the coverage index, $e$, increases, the layoff tax, $\tau_{f_{k}}$, increases and the payroll tax, $\tau$, is cut down. This decrease in the payroll tax makes the surplus of a job-worker match more profitable to the firm, hence increasing job creation and reducing job destruction. In addition, this reduction in the payroll tax increases the value of search for the workers and thus reduces informality.

\section{Conclusion}

This paper studies the effects of the introduction of UC in countries characterized by pervasive informality. It provides a simple framework to analyze the impact of UC on the allocation of workers between formal and informal activities, as well as the allocation of workers between sectors featuring different incentives to go informal.

In this framework, we show that a reasonable amount of UC may reduce informality within each sector, while larger amounts of UC induce large disincentives to go formal because of the level of taxation involved. We also argue that the financing of UC should be part and parcel of a well-thought UC system. As a matter of fact, UC finance based on payroll taxes is likely to entail an excess level of informality resulting from cross-subsidies between sectors with different turnover rates. The introduction of a simple layoff tax that will provide funding to the UC system is then shown to reduce informality, hence highlighting how UC finance may be used as a supplementary instrument to curb informality. More accurately, by making firms internalize the cost of an additional layoff to the UC system, the layoff tax will reduce the cross-subsidies between the two sectors. It will trigger a reallocation of the workers from the high- to the low-turnover sector, as well as a reduction in informality in each sector.

In summary, it turns out that introducing UC along with a well-designed financing scheme is likely to reduce informality in developing countries. We believe our results to be relevant for the policy debate in countries, such as Mexico, that are contemplating introducing UC.

\footnotetext{
${ }^{22}$ See e.g. Mortensen and Pissarides (1999).
} 


\section{References}

Acemoglu, D., "Good jobs versus bad jobs," Journal of Labor Economics, 2001, 19 (1), 1.

_ and R. Shimer, "Productivity gains from unemployment insurance," European Economic Review, 2000, 44 (7), 1195-1224.

Albrecht, J., L. Navarro, and S. Vroman, "The Effects of Labour Market Policies in an Economy with an Informal Sector," The Economic Journal, 2009, 119 (539), 1105-1129.

Anderson, P.M. and B.D. Meyer, "Unemployment Insurance in the United States: layoff incentives and cross subsidies," Journal of Labor Economics, 1993, pp. 70-95.

Atkinson, Anthony B. and John Micklewright, "Unemployment Compensation and Labor Market Transitions: A Critical Review," Journal of Economic Literature, 1991, 29 (4), pp. $1679-1727$.

Basu, A., N. Chau, and R. Kanbur, "Contractual dualism, market power and informality," IZA Discussion Paper No. 5845, 2011.

Belzil, C., "Unemployment insurance and subsequent job duration: Job matching versus unobserved heterogeneity," Journal of Applied Econometrics, 2001, 16 (5), 619-636.

Blanchard, O.J. and J. Tirole, "The joint design of unemployment insurance and employment protection: A first pass," Journal of the European Economic Association, 2008, 6 (1), $45-77$.

Boeri, T. and P. Garibaldi, "Shadow sorting," in NBER International Seminar on Macroeconomics Series, MIT Press, 2005.

Cahuc, P. and A. Zylberberg, "Optimum income taxation and layoff taxes," Journal of Public Economics, 2008, 92 (10), 2003-2019.

_ and F. Malherbet, "Unemployment compensation finance and labor market rigidity," Journal of Public Economics, 2004, 88 (3), 481-501.

Centeno, M. and Á.A. Novo, "Reemployment wages and UI liquidity effect: a regression discontinuity approach," Portuguese Economic Journal, 2009, 8 (1), 45-52.

Charlot, O., F. Malherbet, and C. Terra, "Product Market Regulation, Firm Size, Unemployment and Informality in Developing Economies," IZA Discussion Papers No. 5519, 2011. 
Deere, D.R., "Unemployment insurance and employment," Journal of Labor Economics, 1991, pp. 307-324.

Feldstein, M., "Temporary layoffs in the theory of unemployment," The Journal of Political Economy, 1976, pp. 937-957.

Fields, G.S., "Rural-urban migration, urban unemployment and underemployment, and jobsearch activity in LDCs," Journal of Development Economics, 1975, 2 (2), 165-187.

_ , "Labour market modelling and the urban informal sector: theory and evidence," in The Informal Sector Revisited. Paris, OECD, 1990.

_., "A guide to multisector labor market models," World Bank Social Protection Working Paper, 2005.

_ , "A welfare economic analysis of labor market policies in the Harris-Todaro model," Journal of Development Economics, 2005, 76 (1), 127-146.

Fortin, B., N. Marceau, and L. Savard, "Taxation, wage controls and the informal sector," Journal of Public Economics, 1997, 66 (2), 293-312.

Fredriksson, P. and B. Holmlund, "Improving incentives in unemployment insurance: A review of recent research," Journal of Economic Surveys, 2006, 20 (3), 357-386.

Fugazza, M. and J.F. Jacques, "Labor market institutions, taxation and the underground economy," Journal of Public Economics, 2004, 88 (1), 395-418.

Günther, I. and A. Launov, "Informal employment in developing countries: opportunity or last resort?," Journal of Development Economics, 2012, 97 (1), 88-98.

Harris, J.R. and M. Todaro, "Migration, unemployment and development," American Economic Review, 1970, 60 (1), 126-142.

Hart, K., "Informal income opportunities and urban employment in Ghana," The Journal of Modern African Studies, 1973, 11 (01), 61-89.

Heckman, James J and Carmen Pagés, "The Cost of Job Security Regulation: Evidence from Latin American Labor Markets," NBER Working Papers No. 7r773, 2000.

Heckman, J.J. and C. Pagés, "Law and employment: Lessons from Latin America and the Caribbean," NBER Working Papers No. 10129, 2003. 
Holmlund, B., "Unemployment insurance in theory and practice," The Scandinavian Journal of Economics, 1998, 100 (1), 113-141.

Kugler, Adriana, "The incidence of job security regulations on labor market flexibility and compliance in Colombia: evidence from the 1990 reform," IDB Working Paper R-393, 2000.

Lemieux, T., B. Fortin, and P. Frechette, "The effect of taxes on labor supply in the underground economy," The American economic review, 1994, 84 (1), 231-254.

Lewis, W.A., "Economic development with unlimited supplies of labour," The manchester school, 1954, 2008, 22 (2), 139-191.

Malherbet, F. and M. Ulus, "Unemployment Insurance and Labor Reallocation," CREST Working Papers No. 17, 2003.

Maloney, W.F., "Does informality imply segmentation in urban labor markets? Evidence from sectoral transitions in Mexico," The World Bank Economic Review, 1999, 13 (2), 275-302.

_ , "Informality revisited," World development, 2004, 32 (7), 1159-1178.

Margolis, D., L. Navarro, and D. Robalino, "Unemployment insurance, job search and informal employment," IZA Discussion Papers No. 6660, 2012.

Mead, D.C. and C. Morrisson, "The informal sector elephant," World development, 1996, 24 (10), 1611-1619.

Meghir, C., R. Narita, and J.M. Robin, "Wages and Informality in Developing Countries," NBER Working Papers No. 18347, 2012.

Mortensen, D.T., "Job search and labor market analysis," Handbook of labor economics, 1986, 2, 849-919.

- and C.A. Pissarides, "Job creation and job destruction in the theory of unemployment," The Review of Economic Studies, 1994, 61 (3), 397-415.

_ and _, "New developments in models of search in the labor market," Handbook of labor economics, 1999, 3, 2567-2627.

Ours, J.C. Van and M. Vodopivec, "Does reducing unemployment insurance generosity reduce job match quality?," Journal of Public Economics, 2008, 92 (3), 684-695.

Petrongolo, B. and C.A. Pissarides, "Looking into the black box: A survey of the matching function," Journal of Economic Literature, 2001, 39 (2), 390-431. 
Pratap, S. and E. Quintin, "Are labor markets segmented in developing countries? A semiparametric approach," European Economic Review, 2006, 50 (7), 1817-1841.

Robalino, D., E. Zylberstajn, and J. Robalino, "Incentive effects of risk pooling, redistributive and savings arrangements in unemployment benefit systems: Evidence from a job-search model for Brazil," IZA Discussion Papers No. 5476, 2011.

Rogerson, R., R. Shimer, and R. Wright, "Search-theoretic models of the labor market: A survey," Journal of Economic Literature, 2005, 43 (4), 959-988.

Satchi, M. and J. Temple, "Labor markets and productivity in developing countries," Review of Economic Dynamics, 2009, 12 (1), 183-204.

Schneider, F., A. Buehn, and C.E. Montenegro, Shadow Economies all over the World: New Estimates for 162 Countries from 1999 to 2007, World Bank, 2010.

- and D.H. Enste, "Shadow economies: Size, causes, and consequences," Journal of economic literature, 2000, 38 (1), 77-114.

Tatsiramos, K., "Unemployment insurance in europe: Unemployment duration and subsequent employment stability," Journal of the European Economic Association, 2009, 7 (6), 1225-1260.

Topel, R. and F. Welch, "Unemployment insurance: Survey and extensions," Economica, 1980, 47 (187), 351-379.

Ulyssea, G., "Regulation of entry, labor market institutions and the informal sector," Journal of Development Economics, 2010, 91 (1), 87-99.

Vodopivec, M., "Introducing unemployment insurance to developing countries," IZA Policy Papers No. 6, 2009.

Zenou, Y., "Job search and mobility in developing countries. Theory and policy implications," Journal of Development Economics, 2008, 86 (2), 336-355. 


\section{A Appendix: Study of the model with identical sectors}

Proof. 1. Remember that when the two sectors are identical, the labor market tightness result from:

$$
\frac{\gamma}{q(\theta)}=\frac{y-w}{r+s}
$$

while the wage equation writes:

$$
w=(1-\beta)\left[z+\frac{\beta \gamma}{1-\beta} \theta\right]+\beta y
$$

Combining the above equations, we obtain

$$
\frac{\gamma}{q\left(\theta^{*}\right)}=\frac{(1-\beta)(y-z)-\beta \gamma \theta^{*}}{r+s}
$$

Implicit differentiation gives

$$
\frac{\partial \theta^{*}}{\partial z}=-\frac{(1-\beta) \theta^{*}}{\eta\left[(1-\beta)(y-z)-\beta \gamma \theta^{*}\right]+\beta \gamma \theta^{*}} \leq 0
$$

where $\eta \equiv-\frac{\theta q^{\prime}(\theta)}{q(\theta)} \in[0,1]$ and $q^{\prime}(\theta) \leq 0$, which establishes the first claim of proposition 1 .

2. As the size of informal sector is given by:

$$
M^{*}=F^{\prime-1}\left[r S^{*}\right]
$$

it is sufficient to show $\frac{\partial r S^{*}}{\partial z} \geq 0$ to establish that $\frac{\partial M^{*}}{\partial z} \leq 0$.

As

$$
r S^{*}=(1-\tau)\left[z+\frac{\gamma \beta}{1-\beta} \theta^{*}\right]
$$

for a given $\tau$, we have

$$
\frac{\partial r S^{*}}{\partial z}=(1-\tau)[\underbrace{1}_{\substack{\text { direct effect } \\
(+)}}+\underbrace{\frac{\gamma \beta}{1-\beta} \frac{\partial \theta^{*}}{\partial z}}_{\begin{array}{c}
\text { indirect effect } \\
(-)
\end{array}}]
$$

as emphasized in text.

Substituting (42) in (45), we have:

$$
\begin{aligned}
& \frac{\partial r S^{*}}{\partial z}=(1-\tau)\left[1-\frac{\beta \gamma \theta^{*}}{\eta\left[(1-\beta)(y-z)-\beta \gamma \theta^{*}\right]+\beta \gamma \theta^{*}}\right] \\
& \frac{\partial r S^{*}}{\partial z}=(1-\tau)\left[1-\frac{1}{\eta \frac{(1-\beta)(y-z)-\beta \gamma \theta^{*}}{\beta \gamma \theta^{*}}+1}\right]
\end{aligned}
$$


where $\eta \in[0,1]$. Using (41):

$$
\frac{\partial r S^{*}}{\partial z}=(1-\tau)\left[1-\frac{1}{\eta \frac{r+s}{\beta \theta^{*} q\left(\theta^{*}\right)}+1}\right] \geq 0
$$

establishes that the indirect effect $\frac{-1}{\eta \frac{\gamma(r+s)}{\beta \gamma \theta^{*} q\left(\theta^{*}\right)}+1}$ is always larger than -1 so that it is always outweighed by the direct effect, as indicated in text. Therefore claim (2) of proposition 1 holds.

3. The proof of claim (3) direct stems from the differentiation of the following equation:

$$
u^{*}=\frac{s}{s+\theta^{*} q\left(\theta^{*}\right)}
$$

which implies:

$$
\frac{d u^{*}}{d z}=\frac{d u^{*}}{d \theta^{*}} \frac{\partial \theta^{*}}{\partial z}
$$

where

$$
\begin{aligned}
& \frac{d u^{*}}{d \theta^{*}}=-\frac{s q\left(\theta^{*}\right)(1-\eta)}{\left(s+\theta^{*} q\left(\theta^{*}\right)\right)^{2}} \leq 0 \\
& \frac{\partial \theta^{*}}{\partial z}=-\frac{(1-\beta) \theta^{*}}{\eta\left[(1-\beta)(y-z)-\beta \gamma \theta^{*}\right]+\beta \gamma \theta^{*}} \leq 0
\end{aligned}
$$

Which implies $\frac{d u^{*}}{d z^{*}} \geq 0$, as argued in text. This proves claim 3 .

4. By definition, we have:

$$
L^{*}=\left(1-u^{*}\right)\left(N-M^{*}\right)
$$

with $U^{*}=u^{*}\left(N-M^{*}\right)$ so that

$$
\frac{d L^{*}}{d z}=-\frac{d u^{*}}{d z}\left(N-M^{*}\right)-\left(1-u^{*}\right) \frac{d M^{*}}{d z}
$$

which is ambiguous in general, as $\frac{d u^{*}}{d z} \geq 0$ and $\frac{d M^{*}}{d z} \leq 0$, but can be positive whenever:

$$
-\frac{d M^{*} / d z}{N-M^{*}} \geq \frac{d u^{*} / d z}{1-u^{*}}
$$

as argued in text

\section{B Appendix: Study of the model with heterogenous sectors}

\section{B.1 Proof that formal jobs pay higher wages}

Equation (14) and the arbitrage condition (10) together imply the following expression for informal wages:

$$
w_{I_{k}}^{*}=(1-\tau)\left[z+\frac{\beta \gamma}{1-\beta} \theta^{*}\right]
$$


while using (20) and substituting $p_{k}^{*}$ by its expression (32) implies that after tax formal wages write as:

$$
\omega_{k}^{*} \equiv w_{k}^{*}(1-\tau)=(1-\tau)\left[z+\frac{\beta \gamma \theta^{*}}{1-\beta}+\frac{\beta \gamma\left(r+s_{k}\right)}{q\left(\theta^{*}\right)(1-\beta)}\right]
$$

Then, comparing (54) and (55) establishes that $\omega_{k}^{*}>w_{I_{k}}^{*}>z(1-\tau)$. This proves our claim that formal jobs pay higher wages than informal jobs, and that informal wages are higher than net unemployment compensation.

\section{B.2 Study of the PC curve}

The PC relationship writes:

$$
\alpha^{\frac{1}{1-\rho}}\left[\frac{\gamma\left[r+s_{H}+\beta \theta_{H} q\left(\theta_{H}\right)\right]}{y q\left(\theta_{H}\right)[1-\beta]}+\frac{z}{y}\right]^{\frac{\rho}{\rho-1}}=1-(1-\alpha)^{\frac{1}{1-\rho}}\left[\frac{\gamma\left[r+s_{L}+\beta \theta_{L} q\left(\theta_{L}\right)\right]}{q\left(\theta_{L}\right)[1-\beta] y}+\frac{z}{y}\right]^{\frac{\rho}{\rho-1}}
$$

1. Let us first show that the PC curve defines a decreasing relationship between $\theta_{H}$ and $\theta_{L}$. In this purpose, let us define

$$
\begin{aligned}
\Psi_{1}= & \alpha^{\frac{1}{1-\rho}}\left[\frac{\gamma\left[r+s_{H}+\beta \theta_{H} q\left(\theta_{H}\right)\right]}{q\left(\theta_{H}\right)[1-\beta] y}+\frac{z}{y}\right]^{\frac{\rho}{\rho-1}} \\
& +(1-\alpha)^{\frac{1}{1-\rho}}\left[\frac{\gamma\left[r+s_{L}+\beta \theta_{L} q\left(\theta_{L}\right)\right]}{q\left(\theta_{L}\right)[1-\beta] y}+\frac{z}{y}\right]^{\frac{\rho}{\rho-1}}-1 \\
= & \alpha^{\frac{1}{1-\rho}} p_{H}\left(\theta_{H}\right)^{\frac{\rho}{\rho-1}}+(1-\alpha)^{\frac{1}{1-\rho}} p_{L}\left(\theta_{L}\right)^{\frac{\rho}{\rho-1}}-1
\end{aligned}
$$

with

$$
\partial p_{k} / \partial \theta_{k}=\frac{1}{y}\left[\frac{-\gamma q^{\prime}\left(\theta_{k}\right)\left[r+s_{k}\right]}{q\left(\theta_{k}\right)^{2}[1-\beta]}+\frac{\beta \gamma}{1-\beta}\right] \geq 0 \text { for } k=H, L
$$

Let $\nu=\frac{\rho}{\rho-1}$. Notice that $\nu$ can be positive or negative as $\left.\left.\rho \in\right]-\infty, 1\right]$, however, we have:

$$
\partial \Psi_{1} / \partial \theta_{H}=\alpha^{\frac{1}{1-\rho}} \nu p_{H}\left(\theta_{H}\right)^{\nu-1} \partial p_{H} / \partial \theta_{H}
$$

and

$$
\partial \Psi_{1} / \partial \theta_{L}=(1-\alpha)^{\frac{1}{1-\rho}} \nu p_{L}\left(\theta_{L}\right)^{\nu-1} \partial p_{L} / \partial \theta_{L}
$$

Thus

$$
\partial \theta_{H} / \partial \theta_{L}=-\frac{(1-\alpha)^{\frac{1}{1-\rho}} p_{L}\left(\theta_{L}\right)^{\nu-1} \partial p_{L} / \partial \theta_{L}}{\alpha^{\frac{1}{1-\rho}} p_{H}\left(\theta_{H}\right)^{\nu-1} \partial p_{H} / \partial \theta_{H}} \leq 0
$$

Note that this does not depend on $\nu$ (the term cancels out).

2. Let us now study how the PC curve moves with the various parameters of the model.

Differentiating (32), we have

$$
\partial p_{H} / \partial \gamma \geq 0 ; \partial p_{H} / \partial z \geq 0 ; \partial p_{H} / \partial y \leq 0 ; \partial p_{H} / \beta_{H} \geq 0 ; \partial p_{H} / \partial s_{H} \geq 0
$$


and

$$
\partial p_{L} / \partial \gamma \geq 0 ; \partial p_{L} / \partial z \geq 0 ; \partial p_{L} / \partial y \leq 0 ; \partial p_{L} / \beta_{L} \geq 0 ; \partial p_{L} / \partial s_{L} \geq 0
$$

Thus, differentiating (PC), it turns out that along the PC curve,

$$
\begin{aligned}
& \partial \theta_{H} / \partial \gamma=-\frac{\partial \Psi_{1} / \partial \gamma}{\partial \Psi_{1} / \partial \theta_{H}}=-\left[\frac{\partial p_{H} / \partial \gamma}{\partial p_{H} / \partial \theta_{H}}+\frac{(1-\alpha)^{\frac{1}{1-\rho}} p_{L}^{\nu-1} \partial p_{L} / \partial \gamma}{\alpha^{\frac{1}{1-\rho}} p_{H}^{\nu-1} \partial p_{H} / \partial \theta_{H}}\right] \leq 0 \\
& \partial \theta_{L} / \partial \gamma=-\frac{\partial \Psi_{1} / \partial \gamma}{\partial \Psi_{1} / \partial \theta_{L}}=-\left[\frac{\alpha^{\frac{1}{1-\rho}} p_{H}^{\nu-1} \partial p_{H} / \partial \gamma}{(1-\alpha)^{\frac{1}{1-\rho}} p_{L}^{\nu-1} \partial p_{L} / \partial \theta_{L}}+\frac{\partial p_{L} / \partial \gamma}{\partial p_{L} / \partial \theta_{L}}\right] \leq 0
\end{aligned}
$$

Thus the PC curve shifts down with $\gamma$ as argued in text.

Similarly,

$$
\begin{aligned}
& \partial \theta_{H} / \partial \beta=-\frac{\partial \Psi_{1} / \partial \beta}{\partial \Psi_{1} / \partial \theta_{H}}=-\left[\frac{\partial p_{H} / \partial \beta}{\partial p_{H} / \partial \theta_{H}}+\frac{(1-\alpha)^{\frac{1}{1-\rho}} p_{L}^{\nu-1} \partial p_{L} / \partial \beta}{\alpha^{\frac{1}{1-\rho}} p_{H}^{\nu-1} \partial p_{H} / \partial \theta_{H}}\right] \leq 0 \\
& \partial \theta_{L} / \partial \beta=-\frac{\partial \Psi_{1} / \partial \beta}{\partial \Psi_{1} / \partial \theta_{L}}=-\left[\frac{\alpha^{\frac{1}{1-\rho}} p_{H}^{\nu-1} \partial p_{H} / \partial \beta}{(1-\alpha)^{\frac{1}{1-\rho}} p_{L}^{\nu-1} \partial p_{L} / \partial \theta_{L}}+\frac{\partial p_{L} / \partial \beta}{\partial p_{L} / \partial \theta_{L}}\right] \leq 0
\end{aligned}
$$

Thus PC will also shift down with $\beta$.

$$
\begin{gathered}
\partial \theta_{H} / \partial y=-\frac{\partial \Psi_{1} / \partial y}{\partial \Psi_{1} / \partial \theta_{H}}=-\left[\frac{\partial p_{H} / \partial y}{\partial p_{H} / \partial \theta_{H}}+\frac{(1-\alpha)^{\frac{1}{1-\rho}} p_{L}^{\nu-1} \partial p_{L} / \partial y}{\alpha^{\frac{1}{1-\rho}} p_{H}^{\nu-1} \partial p_{H} / \partial \theta_{H}}\right] \geq 0 \\
\partial \theta_{L} / \partial y=-\frac{\partial \Psi_{1} / \partial y}{\partial \Psi_{1} / \partial \theta_{L}}=-\left[\frac{\alpha^{\frac{1}{1-\rho}} p_{H}^{\nu-1} \partial p_{H} / \partial y}{(1-\alpha)^{\frac{1}{1-\rho}} p_{L}^{\nu-1} \partial p_{L} / \partial \theta_{L}}+\frac{\partial p_{L} / \partial y}{\partial p_{L} / \partial \theta_{L}}\right] \geq 0
\end{gathered}
$$

Thus PC shifts up with $y$.

$$
\begin{gathered}
\partial \theta_{H} / \partial z=-\frac{\partial \Psi_{1} / \partial z}{\partial \Psi_{1} / \partial \theta_{H}}=-\left[\frac{\partial p_{H} / \partial z}{\partial p_{H} / \partial \theta_{H}}+\frac{(1-\alpha)^{\frac{1}{1-\rho}} p_{L}^{\nu-1} \partial p_{L} / \partial z}{\alpha^{\frac{1}{1-\rho}} p_{H}^{\nu-1} \partial p_{H} / \partial \theta_{H}}\right] \leq 0 \\
\partial \theta_{L} / \partial z=-\frac{\partial \Psi_{1} / \partial z}{\partial \Psi_{1} / \partial \theta_{L}}=-\left[\frac{\alpha^{\frac{1}{1-\rho}} p_{H}^{\nu-1} \partial p_{H} / \partial z}{(1-\alpha)^{\frac{1}{1-\rho}} p_{L}\left(\theta_{L}\right)^{\nu-1} \partial p_{L} / \partial \theta_{L}}+\frac{\partial p_{L} / \partial z}{\partial p_{L} / \partial \theta_{L}}\right] \leq 0
\end{gathered}
$$

Thus, PC shifts down with $z$.

$$
\begin{gathered}
\partial \theta_{H} / \partial s_{H}=-\frac{\partial \Psi_{1} / \partial s_{H}}{\partial \Psi_{1} / \partial \theta_{H}}=-\frac{\alpha^{\frac{1}{1-\rho}} \nu p_{H}\left(\theta_{H}\right)^{\nu-1} \partial p_{H} / \partial s_{H}}{\alpha^{\frac{1}{1-\rho}} \nu p_{H}\left(\theta_{H}\right)^{\nu-1} \partial p_{H} / \partial \theta_{H}}=-\frac{\partial p_{H} / \partial s_{H}}{\partial p_{H} / \partial \theta_{H}} \leq 0 \\
\partial \theta_{L} / \partial s_{H}=-\frac{\partial \Psi_{1} / \partial s_{H}}{\partial \Psi_{1} / \partial \theta_{L}}=-\frac{\alpha^{\frac{1}{1-\rho}} p_{H}^{\nu-1} \partial p_{H} / \partial s_{H}}{(1-\alpha)^{\frac{1}{1-\rho}} p_{L}^{\nu-1} \partial p_{L} / \partial \theta_{L}} \leq 0
\end{gathered}
$$

Thus, PC shifts down with $s_{H}$. A similar calculation shows that it also shifts down with $s_{L}$. 


\section{B.3 Proof of Proposition 2}

The PC curve is decreasing while $\mathrm{AC}$ is increasing in the $\left(\theta_{L}, \theta_{H}\right)$ plane, so that there is a unique pair $\left(\theta_{H}^{*}, \theta_{L}^{*}\right)$ solving simultaneously $\mathrm{AC}$ and $\mathrm{PC}$. As in equilibrium, $\theta_{H}^{*}=\theta_{L}^{*}=\theta^{*}$, implicit differentiation of

$$
\alpha^{\frac{1}{1-\rho}}\left[\frac{\gamma\left[r+s_{H}+\beta \theta^{*} q\left(\theta^{*}\right)\right]}{q\left(\theta^{*}\right)[1-\beta] y}+\frac{z}{y}\right]^{\frac{\rho}{\rho-1}}=1-(1-\alpha)^{\frac{1}{1-\rho}}\left[\frac{\gamma\left[r+s_{L}+\beta \theta^{*} q\left(\theta^{*}\right)\right]}{q\left(\theta^{*}\right)[1-\beta] y}+\frac{z}{y}\right]^{\frac{\rho}{\rho-1}}
$$

establishes the comparative statics properties of the equilibrium summarized in Proposition 2. Note that the result does not depend on $\nu=\frac{\rho}{\rho-1}$, as this term cancels out from each expression.

\section{B.4 Proof of proposition 3}

\section{- Effects of $z$ on $r S_{k}^{*}$.}

Using the equilibrium conditions $\theta_{H}^{*}=\theta_{L}^{*}=\theta^{*}$ and $r S_{H}^{*}=r S_{L}^{*}=r S^{*}$ and then differentiating (57) yields

$$
\partial \theta^{*} / \partial z=-\frac{\alpha^{\frac{1}{1-\rho}} \frac{\rho}{\rho-1} p_{H}^{\frac{1}{*^{-1}}} \partial p_{H}^{*} / \partial z+(1-\alpha)^{\frac{1}{1-\rho}} \frac{\rho}{\rho-1} p_{L}^{* \frac{1}{\rho-1}} \partial p_{L}^{*} / \partial z}{\alpha^{\frac{1}{1-\rho}} \frac{\rho}{\rho-1} p_{H}^{*^{\frac{1}{\rho-1}}} \partial p_{H}^{*} / \partial \theta+(1-\alpha)^{\frac{1}{1-\rho}} \frac{\rho}{\rho-1} p_{L}^{*^{\frac{1}{\rho-1}}} \partial p_{L}^{*} / \partial \theta}
$$

substituting $\partial p_{k}^{*} / \partial z$ and $\partial p_{k}^{*} / \partial \theta$ and rearranging, we get:

$$
\partial \theta^{*} / \partial z=-\frac{\alpha^{\frac{1}{1-\rho}} p_{H}^{\frac{1}{\rho-1}}+(1-\alpha)^{\frac{1}{1-\rho}} p_{L}^{*^{\frac{1}{\rho-1}}}}{\alpha^{\frac{1}{1-\rho}} p_{H}^{\frac{1}{*^{\rho-1}}}\left[\frac{-\gamma\left[r+s_{H}\right] q^{\prime}\left(\theta^{*}\right)}{q\left(\theta^{*}\right)^{2}[1-\beta]}+\frac{\beta \gamma}{1-\beta}\right]+(1-\alpha)^{\frac{1}{1-\rho}} p_{L}^{* \frac{1}{\rho-1}}\left[\frac{-\gamma\left[r+s_{L}\right] q^{\prime}\left(\theta^{*}\right)}{q\left(\theta^{*}\right)^{2}[1-\beta]}+\frac{\beta \gamma}{1-\beta}\right]} \leq 0
$$

and therefore:

$$
\frac{\beta \gamma}{1-\beta} \partial \theta^{*} / \partial z=-\frac{\alpha^{\frac{1}{1-\rho}} p_{H}^{*^{\frac{1}{\rho-1}}}+(1-\alpha)^{\frac{1}{1-\rho}} p_{L}^{*^{\frac{1}{\rho-1}}}}{\alpha^{\frac{1}{1-\rho}} p_{H}^{* \frac{1}{\rho-1}}\left[\frac{-\left[r+s_{H}\right] q^{\prime}\left(\theta^{*}\right)}{\beta q\left(\theta^{*}\right)^{2}}+1\right]+(1-\alpha)^{\frac{1}{1-\rho}} p_{L}^{\frac{1}{\rho-1}}\left[\frac{-\left[r+s_{L}\right] q^{\prime}\left(\theta^{*}\right)}{\beta q\left(\theta^{*}\right)^{2}}+1\right]}
$$

Let us now show that $\left|\frac{\beta \gamma}{1-\beta} \partial \theta^{*} / \partial z\right| \leq 1$, or equivalently,

$$
\begin{aligned}
& \alpha^{\frac{1}{1-\rho}} p_{H}^{*^{\frac{1}{\rho-1}}}+(1-\alpha)^{\frac{1}{1-\rho}} p_{L}^{*^{\frac{1}{\rho-1}}} \\
\leq & \alpha^{\frac{1}{1-\rho}} p_{H}^{*^{\frac{1}{\rho-1}}}\left[\frac{-\left[r+s_{H}\right] q^{\prime}\left(\theta^{*}\right)}{\beta q\left(\theta^{*}\right)^{2}}+1\right]+(1-\alpha)^{\frac{1}{1-\rho}} p_{L}^{*^{\frac{1}{\rho-1}}}\left[\frac{-\left[r+s_{L}\right] q^{\prime}\left(\theta^{*}\right)}{\beta q\left(\theta^{*}\right)^{2}}+1\right]
\end{aligned}
$$

Rearranging (61), we get

$$
0 \leq \alpha^{\frac{1}{1-\rho}}\left[p_{H}^{*}\right]^{\frac{1}{\rho-1}}\left[\frac{-\left[r+s_{H}\right] q^{\prime}\left(\theta^{*}\right)}{\beta q\left(\theta^{*}\right)^{2}}\right]+(1-\alpha)^{\frac{1}{1-\rho}}\left[p_{L}^{*}\right]^{\frac{1}{\rho-1}}\left[\frac{-\left[r+s_{L}\right] q^{\prime}\left(\theta^{*}\right)}{\beta q\left(\theta^{*}\right)^{2}}\right]
$$

which establishes that $\left|\frac{\beta \gamma}{1-\beta} \partial \theta^{*} / \partial z\right| \leq 1$. Therefore we obtain

$$
\partial r S^{*} / \partial z=(1-\tau)\left[1+\frac{\beta \gamma}{1-\beta} \partial \theta^{*} / \partial z\right] \geq 0
$$


- Effect of $z$ on $N_{k}^{*}$.

Differentiating the free entry condition (17) at given prices together with the wage equation (20) yields:

$$
\partial \theta_{k} / \partial z=\frac{-1}{\frac{-\gamma q^{\prime}\left(\theta_{k}\right)}{q\left(\theta_{k}\right)^{2}} \frac{r+s_{k}}{1-\beta}+\frac{\beta \gamma}{1-\beta}}
$$

As $s_{H} \geq s_{L},(64)$ implies $\left|\partial \theta_{H} / \partial z\right| \leq\left|\partial \theta_{L} / \partial z\right|$ and then, from (63):

$$
\partial r S_{H} / \partial z \geq \partial r S_{L} / \partial z
$$

Therefore, a rise in $\mathrm{UC}$ will initially make sector $H$ more attractive to the job seekers, so that $N_{H}$ will increase and $N_{L}$ will decrease until the arbitrage condition $\theta_{H}^{*}=\theta_{L}^{*}$ is satisfied.

- Effects of $z$ on $p_{k}^{*}$.

$$
p_{k}^{*}=\frac{1}{y}\left[\frac{\gamma\left(r+s_{k}\right)}{q\left(\theta_{k}^{*}\right)(1-\beta)}+z+\frac{\beta \gamma \theta_{k}^{*}}{1-\beta}\right]
$$

with

$$
\frac{\partial p_{k}^{*}}{\partial z}=\frac{1}{y}[\underbrace{\frac{-\gamma\left(r+s_{k}\right)}{q\left(\theta_{k}^{*}\right)^{2}(1-\beta)} q^{\prime}\left(\theta_{k}^{*}\right) \frac{\partial \theta_{k}^{*}}{\partial z}+\frac{\beta \gamma}{1-\beta} \frac{\partial \theta_{k}^{*}}{\partial z}}_{(-)}+1]
$$

which is a priori ambiguous.

However, differentiating PC, it turns out that

$$
\operatorname{sign}\left\{\frac{\partial p_{H}^{*}}{\partial z}\right\}=-\operatorname{sign}\left\{\frac{\partial p_{L}^{*}}{\partial z}\right\}
$$

while AC implies $\theta_{H}^{*}=\theta_{L}^{*}$ and $\frac{\partial \theta_{H}^{*}}{\partial z}=\frac{\partial \theta_{L}^{*}}{\partial z}=\frac{\partial \theta^{*}}{\partial z}$, so that

$$
\frac{\partial\left(p_{H}^{*}-p_{L}^{*}\right)}{\partial z}=\frac{1}{y}\left[\frac{-\gamma q^{\prime}\left(\theta^{*}\right)\left(s_{H}-s_{L}\right)}{q\left(\theta^{*}\right)^{2}(1-\beta)} \frac{\partial \theta^{*}}{\partial z}\right] \leq 0
$$

Thus (67) and (68) together imply

$$
\frac{\partial p_{H}^{*}}{\partial z} \leq 0 \leq \frac{\partial p_{L}^{*}}{\partial z}
$$

- Effect of $z$ on $M_{k}^{*}$ :

Differentiating (23) with knowledge of (22), we have

$$
\operatorname{sign}\left\{\frac{\partial M_{k}^{*}}{\partial z}\right\}=-\operatorname{sign}\left\{\frac{\partial \frac{r S_{k}^{*}}{p_{k}^{*}}}{\partial z}\right\}
$$

From (22) and (32), we have

$$
\frac{r S_{k}^{*}}{p_{k}^{*}}=\frac{(1-\tau)\left[z+\frac{\beta \gamma \theta_{k}^{*}}{1-\beta}\right]}{\frac{1}{y}\left[\frac{\gamma(r+s)}{q\left(\theta_{k}^{*}\right)(1-\beta)}+z+\frac{\beta \gamma \theta_{k}^{*}}{1-\beta}\right]}=\frac{r S_{k}^{*}}{\frac{1}{y}\left[\frac{\gamma(r+s)}{q\left(\theta_{k}^{*}\right)(1-\beta)}+\frac{r S_{k}^{*}}{1-\tau}\right]}
$$


Differentiating (71) with respect to $z$ yields

$$
\begin{aligned}
\operatorname{sign}\left\{\frac{\partial \frac{r S_{k}^{*}}{p_{k}^{*}}}{\partial z}\right\} & =\operatorname{sign}\left\{\frac{\partial r S_{k}^{*}}{\partial z}\left[\frac{\gamma(r+s)}{q\left(\theta_{k}^{*}\right)(1-\beta)}+\frac{r S_{k}^{*}}{1-\tau}\right]-r S_{k}^{*}\left[\frac{-\gamma q^{\prime}\left(\theta_{k}^{*}\right) \frac{\partial \theta_{k}^{*}}{\partial z}(r+s)}{q\left(\theta_{k}^{*}\right)^{2}(1-\beta)}+\frac{\frac{\partial r S_{k}^{*}}{\partial z}}{1-\tau}\right]\right\} \\
& =\operatorname{sign}\left\{\frac{\partial r S_{k}^{*}}{\partial z}-\eta_{k}^{*} r S_{k}^{*} \frac{\frac{\partial \theta_{k}^{*}}{\partial z}}{\theta_{k}^{*}}\right\}
\end{aligned}
$$

where $\eta_{k}^{*}=-\theta_{k}^{*} \frac{q^{\prime}\left(\theta_{k}^{*}\right)}{q\left(\theta_{k}^{*}\right)} \in[0,1]$. Rearranging a little bit yields

$$
\operatorname{sign}\left\{\frac{\partial \frac{r S_{k}^{*}}{p_{k}^{*}}}{\partial z}\right\}=\operatorname{sign}\left\{\epsilon_{r S_{k}^{*} / z}-\eta_{k}^{*} \epsilon_{\theta_{k}^{*} / z}\right\}
$$

as appears in text. The second term, $-\eta_{k}^{*} \epsilon_{\theta_{k}^{*}} / z$ is positive as $\epsilon_{\theta_{k}^{*}} / z=\frac{z}{\theta_{k}^{*}} \frac{\partial \theta_{k}^{*}}{\partial z} \leq 0$. Let us now show that $\frac{\partial r S_{k}^{*}}{\partial z}=(1-\tau)\left[1+\frac{\beta \gamma \partial \theta^{*} / \partial z}{1-\beta}\right]$, is also positive, so that $\epsilon_{r S_{k}^{*}} / z=\frac{z}{r S_{k}^{*}} \frac{\partial r S_{k}^{*}}{\partial z} \geq 0$.

(63) together with (73) imply

$$
\operatorname{sign}\left\{\epsilon_{r S_{k}^{*} / z}-\eta_{k}^{*} \epsilon_{\theta_{k}^{*} / z}\right\} \geq 0
$$

as claimed in (34), and thus

$$
\frac{\partial \frac{r S_{k}^{*}}{p_{k}^{*}}}{\partial z} \geq 0
$$

On its turn, (70) and (75) lead to

$$
\frac{\partial M_{k}^{*}}{\partial z} \leq 0
$$

as claimed in proposition 3 .

\section{- Effect of $z$ on $u_{k}^{*}$.}

Differentiating (9),

$$
\frac{\partial u_{k}^{*}}{\partial z}=-\frac{q\left(\theta_{k}^{*}\right)\left[1-\eta_{k}^{*}\right]}{\left[s_{k}+\theta_{k}^{*} q\left(\theta_{k}^{*}\right)\right]^{2}} \frac{\partial \theta_{k}^{*}}{\partial z} \geq 0
$$

as $\frac{\partial \theta_{k}^{*}}{\partial z} \leq 0$, as established by proposition 2 .

- Effect of $z$ on $L_{k}^{*}$.

As

$$
L_{H}^{*}=\left(1-u_{H}^{*}\right)\left(N_{H}^{*}-M_{H}^{*}\right)
$$

implies

$$
\frac{\partial L_{H}^{*}}{\partial z}=\underbrace{-\frac{\partial u_{H}^{*}}{\partial z}\left(N_{H}^{*}-M_{H}^{*}\right)}_{(-)}+\underbrace{\left(1-u_{H}^{*}\right)\left(\frac{\partial N_{H}^{*}}{\partial z}-\frac{\partial M_{H}^{*}}{\partial z}\right)}_{(+)}
$$

as from claims 2,3 and 4 of proposition 3, we have $: \frac{\partial M_{H}^{*}}{\partial z} \leq 0 ; \frac{\partial N_{H}^{*}}{\partial z} \geq 0 ; \frac{\partial u_{H}^{*}}{\partial z} \geq 0$. 
Similarly,

$$
\frac{\partial L_{L}^{*}}{\partial z}=\underbrace{-\frac{\partial u_{L}^{*}}{\partial z}\left(N_{L}^{*}-M_{L}^{*}\right)+\left(1-u_{L}^{*}\right) \frac{\partial N_{L}^{*}}{\partial z}}_{(-)}+\underbrace{\left(1-u_{L}^{*}\right)\left(-\frac{\partial M_{L}^{*}}{\partial z}\right)}_{(+)}
$$

as from claims 2,3 and 4 of proposition 3 , we have $: \frac{\partial M_{H}^{*}}{\partial z} \leq 0 ; \frac{\partial N_{L}^{*}}{\partial z} \leq 0 ; \frac{\partial u_{L}^{*}}{\partial z} \geq 0$.

\section{Appendix C : unemployment compensation finance and en- dogenous job destruction}

We consider an extension of the model that generalizes our benchmark model by making layoff's decisions endogenous. We proceed as in Mortensen and Pissarides (1994), and we introduce a layoff tax to finance the UI system. In what follows, the productivity $y$ is random, drawn from a stationary distribution $G(y)$ distributed across the interval $\left[y^{\min }, y^{\max }\right]$. The stochastic process governing productivity changes is Poisson with arrival rate $\lambda_{k}$. When productivity changes, there is a new draw from the stationary distribution $G(y)$. Jobs are destroyed whenever productivity drops below an endogenous threshold $R_{k}$ (see below). As is conventional in the literature, the layoff tax alters wage bargaining and implies a two-tier bargaining structure: the layoff tax applies once the worker is hired, while it does not apply and cannot be binding upon first negotiation, since no contract has yet been signed, so that the firm does not incur any penalty in case of disagreement. Therefore, we distinguish the wage negotiation upon first meeting (indexed by $o$ ) from the wage renegotiation (indexed by $i$ ).

\section{C.1 Bellman equations}

As in Mortensen and Pissarides (1994), it is assumed that the productivity of new matches is equal to the upper bound of the distribution, $y^{\max }$. With the same notations as before, the Bellman's equations read:

$$
\begin{aligned}
r V_{k} & =-\gamma+q\left(\theta_{k}\right)\left[J_{o_{k}}\left(y^{\max }\right)-V_{k}\right] \\
r J_{o_{k}}\left(y^{\max }\right) & =p_{k} y^{\max }-w_{o_{k}}\left(y^{\max }\right)+\lambda_{k}\left[\int \max \left[J_{i_{k}}(\zeta), V_{k}-\tau_{f_{k}}\right] \mathrm{d} G_{k}(\zeta)-J_{o_{k}}\left(y^{\max }\right)\right] \\
r J_{i_{k}}(y) & =p_{k} y-w_{i_{k}}(y)+\lambda_{k}\left[\int \max \left[J_{i_{k}}(\zeta), V_{k}-\tau_{f_{k}}\right] \mathrm{d} G_{k}(\zeta)-J_{i_{k}}(y)\right] \\
r S_{k} & =z(1-\tau)+\theta_{k} q\left(\theta_{k}\right)\left[W_{o_{k}}\left(y^{\max }\right)-S_{k}\right] \\
r W_{o_{k}}\left(y^{\max }\right) & =w_{o_{k}}\left(y^{\max }\right)(1-\tau)+\lambda_{k}\left[\int \max \left[W_{i_{k}}(\varepsilon), \bar{S}\right] \mathrm{d} G_{k}(\zeta)-W_{o_{k}}\left(y^{\max }\right)\right] \\
r W_{i_{k}}(y) & =w_{i_{k}}(y)(1-\tau)+\lambda_{k}\left[\int \max \left[W_{i_{k}}(\varepsilon), \bar{S}\right] \mathrm{d} G_{k}(\zeta)-W_{i_{k}}(y)\right]
\end{aligned}
$$




\section{C.2 Layoff tax and budget constraint}

We define the formal employment in sector $k$ as $L_{k}=L_{o_{k}}+L_{i_{k}}$. Let $\tau_{f_{k}}=\frac{e z}{r+\theta_{k} q\left(\theta_{k}\right)}$ be the layoff tax as defined in the text and let $\omega_{k}$ denotes the average wage bill in sector $k$ where $\omega_{k}$ is defined as :

$$
\omega_{k}=L_{o_{k}}\left(y^{\max }\right)+L_{i_{k}} \int_{R_{k}}^{y^{\max }} w_{i_{k}}(\zeta) \frac{\mathrm{d} G(\zeta)}{1-G\left(R_{k}\right)}
$$

The budget constraint satisfies :

$$
\underbrace{\tau \sum\left(\omega_{k}+z U_{k}\right)}_{\text {Payroll Taxes }}+\underbrace{\sum L_{k} s_{k} \tau_{f_{k}}}_{\text {Layoff Taxes }}=\sum z U_{k}
$$

where $s_{k} \equiv \lambda_{k} G\left(R_{k}\right)$ is the endogenous separation rate. Rearranging, we get the tax rate as appear in the text.

\section{C.3 Surpluses, bargaining and equilibrium conditions}

Let $\Omega_{o_{k}}\left(y^{\max }\right)=W_{o_{k}}\left(y^{\max }\right)-S_{k}+J_{o_{k}}\left(y^{\max }\right)-V_{k}$ and $\Omega_{i_{k}}(y)=W_{i_{k}}(y)-S_{k}+J_{i_{k}}(y)-V_{k}+\tau_{f_{k}}$ be the total surpluses upon first meeting and continuing labor relationship respectively. Using $W_{i_{k}}(y)$ and $J_{i_{k}}(y)$, the surplus $\Omega_{i_{k}}(y)$ rewrites:

$$
\left(r+\lambda_{k}\right) \Omega_{i_{k}}(y)=p_{k} y-w_{i_{k}}(y) \tau+r \tau_{f_{k}}+\lambda_{k} \int_{R_{k}}^{y^{\max }} \Omega_{i_{k}}(\zeta) \mathrm{d} G_{k}(\zeta)-r S_{k}
$$

The surplus is split between the firm and the worker according to a generalized Nash criterion. The focs to the bargaining problems yield :

$$
\begin{aligned}
\frac{\beta}{1-\beta}(1-\tau)\left(J_{o_{k}}\left(y^{\max }\right)-V_{k}\right) & =W_{o_{k}}\left(y^{\max }\right)-S_{k} \\
\frac{\beta}{1-\beta}(1-\tau)\left(J_{i_{k}}(y)-V_{k}+\tau_{e_{k}}\right) & =W_{i_{k}}(y)-S_{k}
\end{aligned}
$$

Proceeding with the same logic as in the text and assuming free entry $V_{k}=0$, the wages verify:

$$
\begin{gathered}
w_{i_{k}}(y)=\beta\left(p_{k} y+r \tau_{f_{k}}\right)+\frac{1-\beta}{1-\tau} r S \\
w_{o_{k}}\left(y^{\max }\right)=\beta\left(p_{k} y^{\max }-\lambda \tau_{f_{k}}\right)+\frac{1-\beta}{1-\tau} r S
\end{gathered}
$$

where $r S$ is still defined by (22).

The formal condition for proceeding with a match is $\Omega_{i_{k}}(y) \geq 0$. Severance between the employer and the employee occurs as soon as the productivity drops below the reservation value $R_{k}$. The formal condition for severance satisfy $\Omega_{i_{k}}\left(R_{k}\right)=0$. Using this condition together with (77) and combining with (78), the surplus may rewrite as:

$$
\Omega_{i_{k}}(y)=\frac{p_{k}\left(y-R_{k}\right)(1-\tau \beta)}{r+\lambda_{k}}
$$


Then plugging this expression and (78) into (77) and evaluating at $R_{k}$, one gets:

$$
\frac{r S_{k}}{1-\tau}=p_{k} R_{k}+r \tau_{f_{k}}+\frac{\lambda_{k} p_{k}}{r+\lambda_{k}} \int_{R_{k}}^{y^{\max }}\left(\zeta-R_{k}\right) \mathrm{d} G_{k}(\zeta)
$$

Then using (22), one gets the equilibrium conditions defining the reservation productivity $R_{k}$ as appear in the text.

It remains to define the job creation condition. Using the free entry condition together with $J_{o_{k}}\left(y^{\max }\right)$ and using the sharing rules, we have that $\frac{\gamma_{k}}{q\left(\theta_{k}\right)}=J_{o_{k}}\left(y^{\max }\right)=\frac{1-\beta}{1-\tau \beta} \Omega_{o_{k}}\left(y^{\max }\right)$. Owing to the fact that the two surpluses are linked by the following relationship $\Omega_{o_{k}}\left(y^{\max }\right)=$ $\Omega_{i_{k}}\left(y^{\max }\right)-\tau_{e_{k}}(1+\tau)$, the job creation condition rewrites:

$$
\frac{\gamma_{k}}{q\left(\theta_{k}\right)}=\frac{1-\beta}{1-\tau \beta}\left[\Omega_{i_{k}}\left(y^{\max }\right)-\tau_{f_{k}}(1+\tau)\right]
$$

Finally, combining with (80) evaluated at $y^{\max }$, one gets the job creation condition as appear in the text. 


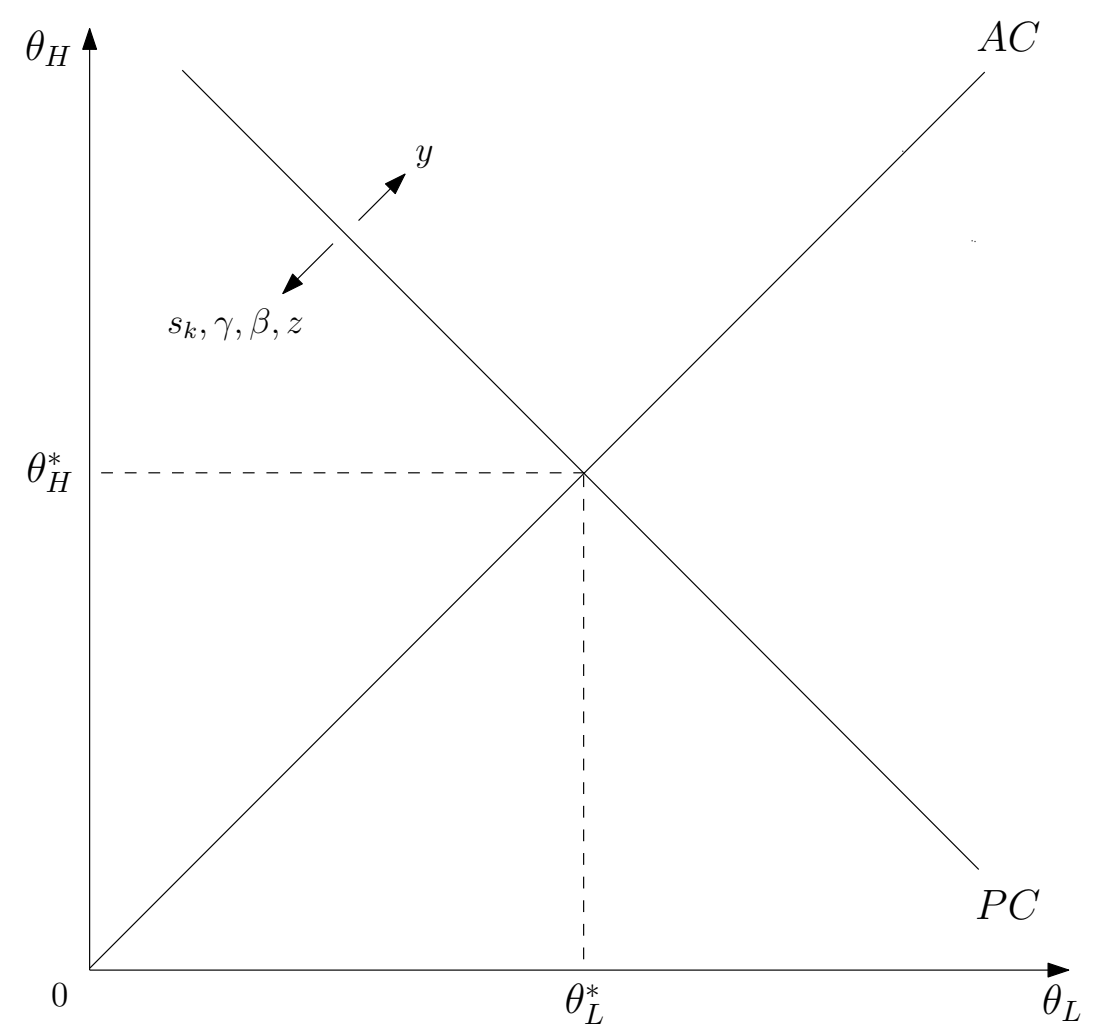

Figure 1: Labor market equilibrium 

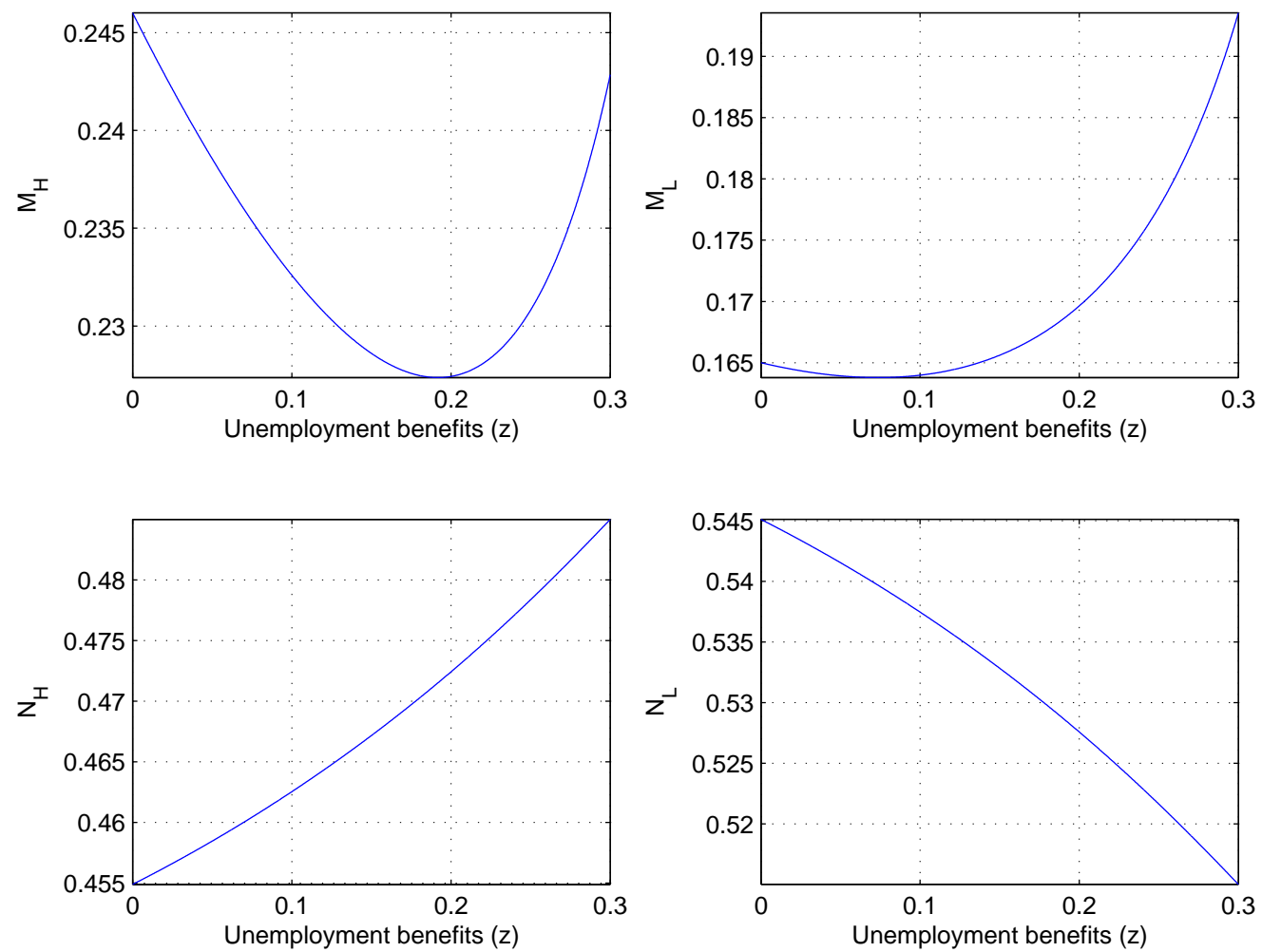

Figure 2: Effects of an increase in unemployment compensation.

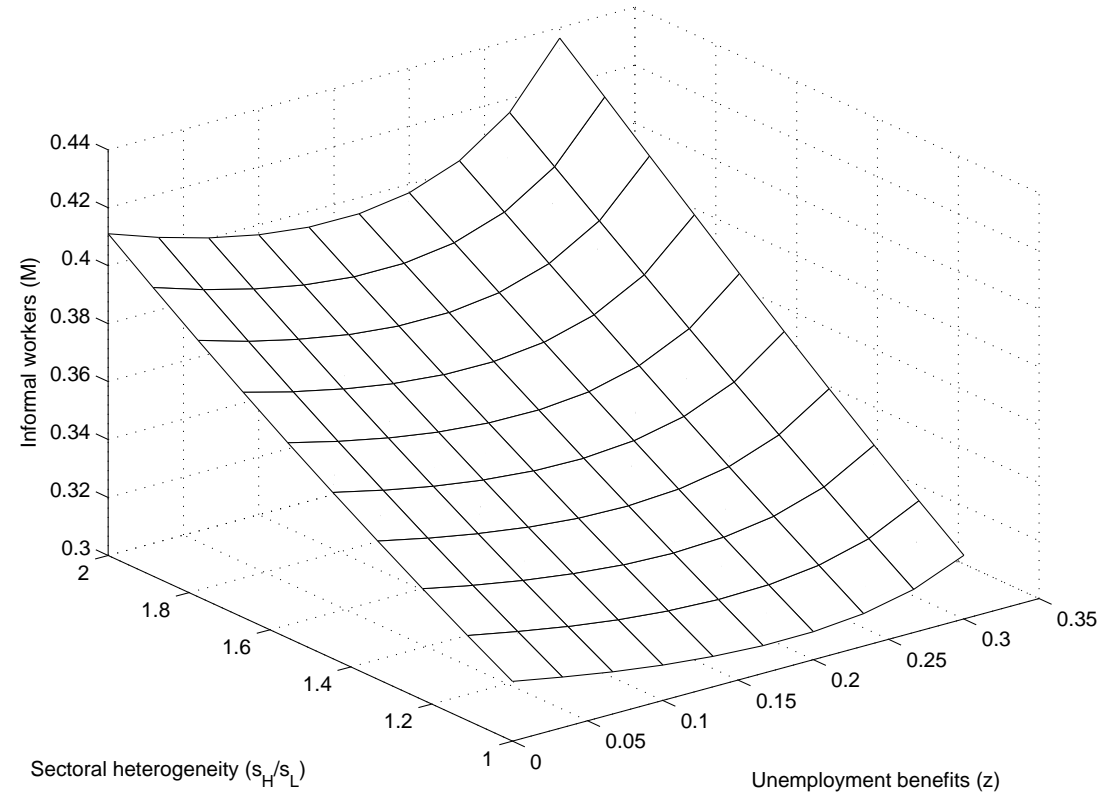

Figure 3: Effects of unemployment compensation and inter-sectoral heterogeneity on informality. 


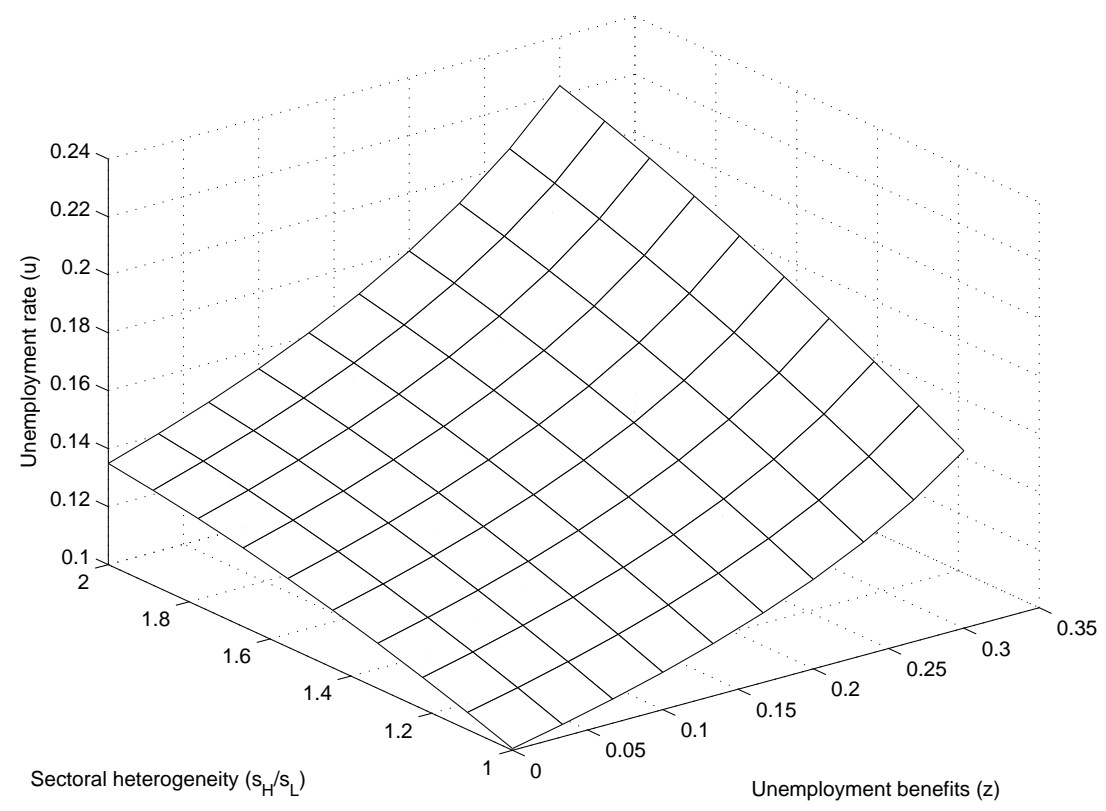

Figure 4: Effects of unemployment compensation and inter-sectoral heterogeneity on unemployment.
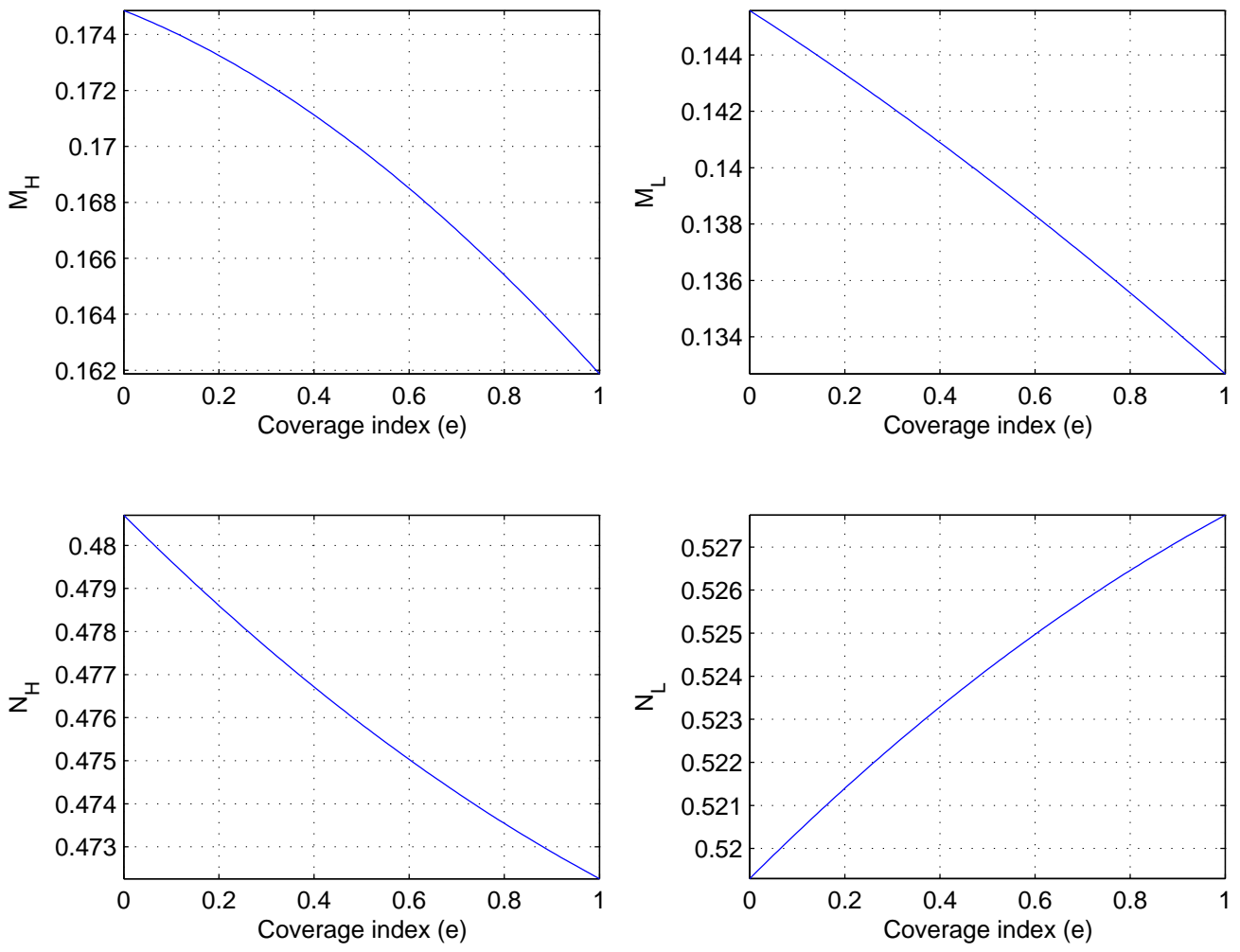

Figure 5: Effects of an increase in the layoff's tax index. 


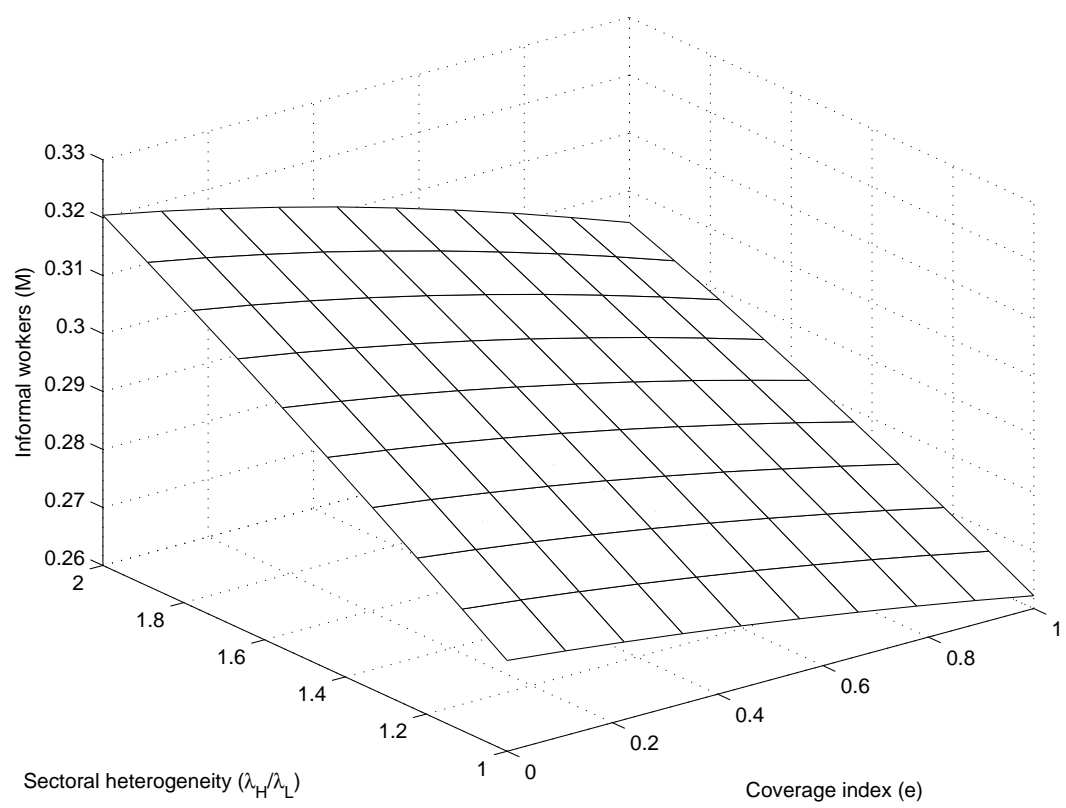

Figure 6: Effects of the layoff's tax and inter-sectoral heterogeneity on informality.

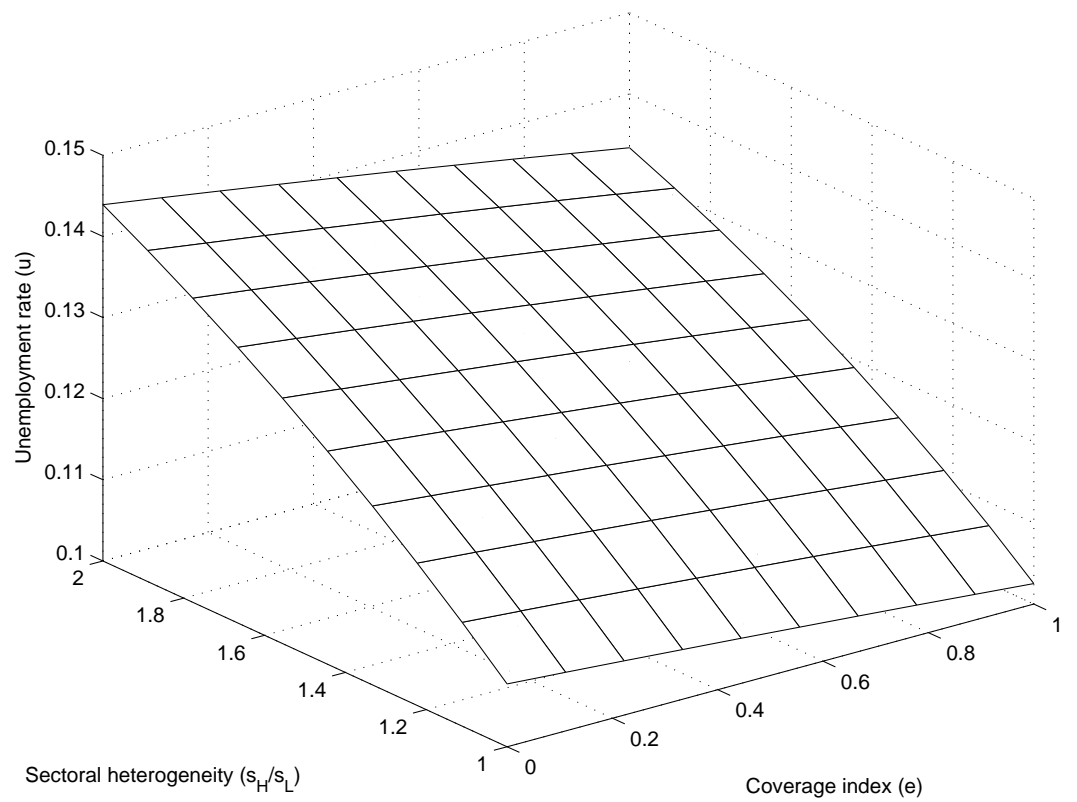

Figure 7: Effects of the layoff's tax and inter-sectoral heterogeneity on unemployment. 